\title{
Three-Dimensional Carbon Nanostructures for Advanced Lithium-Ion Batteries
}

\author{
Chiwon Kang ${ }^{1,+}$, Eunho Cha ${ }^{1, \dagger}$, Mumukshu D. Patel ${ }^{1,+}{ }^{+}$H. Felix $W_{u}{ }^{2}$ and Wonbong Choi ${ }^{1,3, *}$ \\ 1 Department of Materials Science and Engineering, University of North Texas, North Texas Discovery Park \\ 3940 North Elm St. Suite E-132, Denton, TX 76207, USA; ChiWon.Kang@unt.edu (C.K.); \\ EunhoCha@my.unt.edu (E.C.); MumukshuPatel@my.unt.edu (M.D.P.) \\ 2 Vehicle Technologies Office, Office of Energy Efficiency and Renewable Energy, U.S. Department of Energy, \\ 1000 Independence Ave., SW, Washington, DC 20585, USA; Felix.Wu@ee.doe.gov \\ 3 Department of Mechanical and Energy Engineering, University of North Texas, North Texas Discovery Park \\ 3940 North Elm St. Suite E-132, Denton, TX 76207, USA \\ * Correspondence: Wonbong.Choi@unt.edu; Tel.: +1-940-369-7673 \\ + These authors contributed equally to this work.
}

Academic Editor: I. Francis Cheng

Received: 29 July 2016; Accepted: 13 October 2016; Published: 26 October 2016

\begin{abstract}
Carbon nanostructural materials have gained the spotlight as promising anode materials for energy storage; they exhibit unique physico-chemical properties such as large surface area, short $\mathrm{Li}^{+}$ion diffusion length, and high electrical conductivity, in addition to their long-term stability. However, carbon-nanostructured materials have issues with low areal and volumetric densities for the practical applications in electric vehicles, portable electronics, and power grid systems, which demand higher energy and power densities. One approach to overcoming these issues is to design and apply a three-dimensional (3D) electrode accommodating a larger loading amount of active anode materials while facilitating $\mathrm{Li}^{+}$ion diffusion. Furthermore, 3D nanocarbon frameworks can impart a conducting pathway and structural buffer to high-capacity non-carbon nanomaterials, which results in enhanced $\mathrm{Li}^{+}$ion storage capacity. In this paper, we review our recent progress on the design and fabrication of 3D carbon nanostructures, their performance in Li-ion batteries (LIBs), and their implementation into large-scale, lightweight, and flexible LIBs.
\end{abstract}

Keywords: three-dimensional carbon nanostructures; Li-ion batteries; carbon nanotubes; graphene; nanoporous carbon; areal and volumetric density; silicon; hybrid anode; flexible Li-ion battery; areal and volumetric capacity

\section{Introduction}

Novel, economical, and sustainable energy storage systems have emerged as a response to the needs of modern society and rising ecological concerns [1]. The excellent electrochemical properties and unique designs of the electrode materials in Li-ion batteries (LIBs) make them strong contenders for the development of large-scale, advanced transportation (e.g., electric vehicles) and smart grid applications [2]. The commercial use of graphitic carbon-based anode materials is justified by their relatively low cost, excellent structural integrity for the insertion and extraction of $\mathrm{Li}^{+}$ions, safety (free from Li dendrite formation), and formation of a protective passivation layer against many electrolytes (i.e., solid electrolyte interphase (SEI)) [3]. Nevertheless, a low specific capacity of graphite (372 $\mathrm{mAh} \cdot \mathrm{g}^{-1}$, the stoichiometric formula- $\mathrm{LiC}_{6}$ ) is a critical limitation [4]; as a result, they potentially hinder the advance of large-scale energy storage systems that demand high energy and power densities. Thus, carbon nanostructures including carbon nanotubes, graphene, and nanoporous carbon have gained a fair amount of attention due to their superior specific capacities over graphite. Such a superior capacity is largely attributed to the unique features of carbon nanostructures, including high surface 
area for large $\mathrm{Li}^{+}$ion accommodation, exceptional electrical and thermal conductivities, structural flexibility, short $\mathrm{Li}^{+}$ion diffusion length, and broad electrochemical window [4-8].

There have been numerous reports on the LIB performance of nanostructured carbons (e.g., carbon nanotubes (CNTs), graphene, and nanoporous carbon) with diverse structures and morphologies through various synthetic methods. CNTs have been verified as promising anode nanomaterials due to their excellent electrochemical properties [9-21]. Our research team recently reported exceptionally high and stable reversible capacities of $\sim 900 \mathrm{mAh} \cdot \mathrm{g}^{-1}$ at $372 \mathrm{~mA} \cdot \mathrm{g}^{-1}$ or $1 \mathrm{C}$ (time for complete discharge in reciprocal hours) from CNTs directly grown on a $\mathrm{Cu}$ substrate [22]; we also demonstrated that the atomic layer deposition (ALD) alumina $\left(\mathrm{Al}_{2} \mathrm{O}_{3}\right)$ coated $\mathrm{CNTs}$ on $\mathrm{Cu}$ showed a specific capacity of $\sim 1100 \mathrm{mAh} \cdot \mathrm{g}^{-1}$ [23]. Furthermore, graphene [6,24-26] and nanoporous carbon $[27,28]$ based anode materials have been widely investigated to enhance $\mathrm{Li}^{+}$ion intercalation capability.

However, there are still technical challenges remaining to be overcome in the practical application of carbon nanostructures to commercial products [29], including: (1) most of the reported carbon nanostructures with high specific capacity are dimensionally limited to thin-film scale, which is unsuitable for use in large-scale LIBs; (2) carbon nanostructures have an intrinsically low bulk density [30] (most nanomaterial-based electroactive materials show a bulk density of less than $1 \mathrm{~g} \cdot \mathrm{cm}^{-3}$, lower than the commercial-grade graphite $\left.\left(0.35 \sim 0.9 \mathrm{~g} \cdot \mathrm{cm}^{-3}\right)[31,32]\right)$; the low bulk density results in low volumetric capacity, which is inadequate for large-scale energy storage systems [33]. To circumvent the aforementioned limitations, design of 3D carbon nanostructure is one of the most viable approaches to accommodating the large loading amounts of nanocarbon-based electroactive materials. High loading amounts of carbon nanomaterials result in high capacities and a large surface area for the large-scale integration [34]. In addition, the nanoscale porous 3D structure is suited to facilitate $\mathrm{Li}^{+}$ion and electron charge transfer through the electrolyte and bulk electrode into and from the electroactive materials [35]. Pioneering efforts have been made to design the following substrate architectures: a self-assembled 3D bicontinuous nanoarchitecture [35,36], carbon papers [37], aluminum nanorods [38], nanoporous nickel [39], copper (Cu) pillar array [40], stainless steel mesh [41], and polymer scaffold [42].

In a previous report [33], we demonstrated a mathematical model to calculate the surface area of the 3D Cu mesh structure, which suggests that the surface area increases proportionally to the structure thickness and is optimized at the intermediate hole size (Figure 1). The detailed mathematical calculation may be referred to in our past publication (see Supplementary Information, [33]). Although we applied the 3D cuboid structure to justify the dependence of the surface area on both thickness and hole size, a similar trend would be observed in other 3D structures with various hole morphologies such as circular and triangular when viewed from above. In this model, a 3D Cu mesh with $50 \mu \mathrm{m}$ thickness and $65 \mu \mathrm{m}$ hole size corresponds to a nearly $60 \%$ increase in surface area, normalized by its 2D Cu counterpart. In contrast, CNTs grown directly on a 3D Cu mesh with the same dimensions had an areal density of $\sim 2.8 \mathrm{mg} \cdot \mathrm{cm}^{-2}$, which is $\sim 400 \%$ higher than its $2 \mathrm{D}$ counterpart. The slight discrepancy between the theoretical calculations and empirical results could be attributed to the effect of processing parameters of chemical vapor deposition (CVD) (e.g., temperature and time of CNT growth) on the properties of CNTs (e.g., their diameters, lengths, and densities). As expected, the overall capacities of 3D CNTs were superior to those of 2D CNTs due to their higher surface area, which induces greater $\mathrm{Li}^{+}$ion accommodation (a detailed discussion will be presented in Section 3.7). Similarly, Cheah et al. demonstrated an anode comprising ALD-coated $\mathrm{TiO}_{2}$ on a 3D aluminum nanorod current collector, which showed a high rate capability and a 10-fold superior areal capacity $\left(0.0112 \mathrm{mAh} \cdot \mathrm{cm}^{-2}\right)$ to the same electroactive materials on a 2D aluminum plate [38]. Gregorczyk et al. fabricated a core/shell anode structure composed of ALD-coated $\mathrm{RuO}_{2}$ on a 3D CNT sponge with a capacity of $806 \mathrm{mAh} \cdot \mathrm{g}^{-1}$, a 50 -fold higher areal capacity $\left(1.6 \mathrm{mAh} \cdot \mathrm{cm}^{-2}\right)$ than its planar (2D) $\mathrm{RuO}_{2}$ counterpart [43]. 


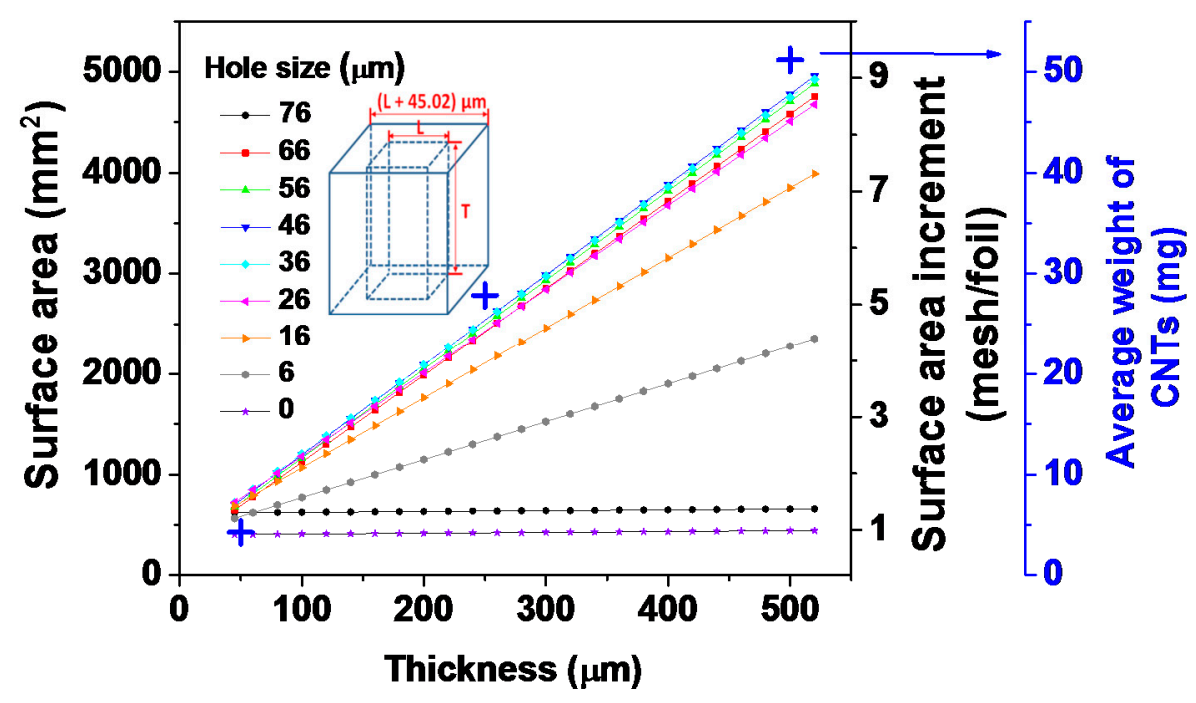

Figure 1. The surface area variation of 3D Cu mesh, its normalized increment by 2D Cu foil, and the empirically measured average weight of CNTs as a function of thickness and hole size. Note that the inset represents a unit cell of the 3D Cu cuboid with its dimension (Reprinted with permission from [33]. Copyright (2012) Elsevier.).

There are some investigations and review articles that cover different facets of carbon nanomaterials for energy applications [4,44-47]. Here we present the first comprehensive review discussing recently reported 3D hybrid architectures comprising nanocarbon and high-capacity nanomaterials for LIB anodes. We further concentrate on our recent advancements in terms of 3D nanostructured carbon materials for energy storage. The majority of the applications will be presented in the form of LIBs; however, the CNTs-graphene-metal seamless structure (Section 3.5) will be discussed in terms of supercapacitor application. The fabrications and properties of 3D multi-layered CNTs, 3D free-standing CNTs, 3D nanocarbon-based hybrid anodes, and CNTs-graphene-metal seamless composites will be intensively explored. Their promising applications in both LIBs and supercapacitors are then thoroughly investigated, with a focus on flexible device integration. Finally, this review will conclude with a brief discussion of current technical challenges and future directions.

\section{Literature Survey}

Next-generation Li-ion batteries demand high energy and power densities, which are largely obtained from the high capacity of electroactive materials. The conventional graphite-based anode and metal oxides cathode materials show lower theoretical specific capacities (e.g., $\mathrm{LiCoO}_{2}\left(274 \mathrm{mAh} \cdot \mathrm{g}^{-1}\right)$, $\mathrm{LiMn}_{2} \mathrm{O}_{4}\left(148 \mathrm{mAh} \cdot \mathrm{g}^{-1}\right)$, and $\left.\mathrm{LiFePO}_{4}\left(170 \mathrm{mAh} \cdot \mathrm{g}^{-1}\right)\right)$ compared to silicon (3579 $\mathrm{mAh} \cdot \mathrm{g}^{-1}$, $\left.\mathrm{Li}_{15} \mathrm{Si}_{4}\right)$ and transition metal oxides (e.g., $\mathrm{NiO}\left(718 \mathrm{mAh} \cdot \mathrm{g}^{-1}\right), \mathrm{SnO}_{2}\left(782 \mathrm{mAh} \cdot \mathrm{g}^{-1}\right)$, and $\mathrm{Fe}_{2} \mathrm{O}_{3}$ $\left.\left(1007 \mathrm{mAh} \cdot \mathrm{g}^{-1}\right)\right)$. However, these high-capacity nanomaterials show an insulating nature and structural instability during prolonged charge and discharge cycles. Hence, one approach to tackle these drawbacks is to design a hybrid anode for LIBs by incorporating carbon-based nanomaterials into the high-capacity nanomaterials. In this section, we cover the recent reports on hybrid anodes for LIBs integrated with three main 3D carbon nanomaterials, carbon nanotubes, graphene, and nanoporous carbon. Table 1 shows selected fabrication methods and charge capacities of 3D carbon nanomaterial-based anode structures for LIBs. 
Table 1. Comparison of fabrication methods and charge capacities of 3D carbon nanomaterial-based anode for LIBs.

\begin{tabular}{|c|c|c|c|c|c|}
\hline $\begin{array}{l}\text { 3D Carbon-Based } \\
\text { Anode Nanostructure }\end{array}$ & Synthetic Method & Charge Capacity & $\begin{array}{l}\text { C-Rate }(\mathrm{C}) \text { or } \\
\text { Current Density } \\
\left(\mathrm{mA} \cdot \mathrm{g}^{-1}\right)\end{array}$ & $\begin{array}{c}\text { Overall/1st Cycle } \\
\text { Coulombic } \\
\text { Efficiency (\%) }\end{array}$ & Reference \\
\hline $\begin{array}{c}\text { Vertically aligned } \\
\text { free-standing 3D CNTs }\end{array}$ & CVD & $490 \mathrm{mAh} \cdot \mathrm{g}^{-1}$ & $\mathrm{~N} / \mathrm{A}$ & $\mathrm{N} / \mathrm{A}$ & [9] \\
\hline $\begin{array}{l}\text { 3D amorphous } \mathrm{Si}-\mathrm{CNTs} \\
\text { directly grown on } \mathrm{Cu} \\
\text { current collector }\end{array}$ & $\begin{array}{l}\text { CVD and sputter } \\
\text { deposition }\end{array}$ & $\begin{array}{l}356 \mathrm{mAh} \cdot \mathrm{g}^{-1} \\
334 \mathrm{mAh} \cdot \mathrm{g}^{-1}\end{array}$ & $\begin{array}{l}1 \mathrm{C} \\
5 \mathrm{C}\end{array}$ & $\sim 99 \% / \sim 67 \%$ & [33] \\
\hline $\begin{array}{c}\text { 3D Core Shell } \\
\text { Multiwalled Carbon } \\
\text { Nanotube@ } @ \mathrm{RuO}_{2}\end{array}$ & ALD & $\sim 600 \mu \mathrm{Ah} \cdot \mathrm{cm}^{-2}$ & $\mathrm{~N} / \mathrm{A}$ & $\sim 88 \% / \sim 91 \%$ & [43] \\
\hline $\begin{array}{c}\text { Multistacked layers of } \\
\text { porous } \mathrm{Co}_{3} \mathrm{O}_{4} \\
\text { nanoplates wrapped by } \\
\text { capillary-like CNT nets }\end{array}$ & $\begin{array}{l}\text { Layer-by-layer (LBL) } \\
\text { structure }\end{array}$ & $\begin{array}{l}>1000 \mathrm{mAh} \cdot \mathrm{g}^{-1} \\
\sim 710 \mathrm{mAh} \cdot \mathrm{g}^{-1}\end{array}$ & $\begin{array}{l}5 \mathrm{~A} \cdot \mathrm{g}^{-1} \\
50 \mathrm{~A} \mathrm{~g}^{-1}\end{array}$ & $97 \% / \sim 75 \%$ & [48] \\
\hline $\begin{array}{l}\text { 3D free-standing } \\
\text { CNTs-graphene }\end{array}$ & CVD & $\begin{array}{l}2 \mathrm{mAh} \cdot \mathrm{cm}^{-2}(\mathrm{coin} \\
\text { cell }) / 0.25 \mathrm{mAh} \cdot \mathrm{cm}^{-2} \\
\text { and } 300 \mathrm{mAh} \cdot \mathrm{cm}^{-3} \\
\quad(\text { flexible cell })\end{array}$ & $0.1 \mathrm{C}$ & $99 \% / \sim 44 \%$ & [49] \\
\hline $\begin{array}{l}3 \mathrm{D} \text { MWCNT } / \mathrm{V}_{2} \mathrm{O}_{5} \\
\text { Core/Shell Sponge }\end{array}$ & ALD & $816 \mu \mathrm{Ah} \cdot \mathrm{cm}^{-2}$ & $1 \mathrm{C}$ & $\sim 99 \% / \mathrm{N} / \mathrm{A}$ & [50] \\
\hline 3D Si-CNT sponges & $\begin{array}{l}\text { Dichlorobenzene-based } \\
\text { CVD for CNT growth } \\
\text { and } \mathrm{SiH}_{4} / \text { Ar-based } \\
\text { CVD for Si nanoparticles }\end{array}$ & $\sim 1300 \mathrm{mAh} \cdot \mathrm{g}^{-1}$ & $0.2 \mathrm{C}$ & $\sim 97 \% / 83 \%$ & [51] \\
\hline $\begin{array}{c}\mathrm{Li}_{4} \mathrm{Ti}_{5} \mathrm{O}_{12} \text { (anode) } \\
\text { imbedded in 3D CNT } \\
\text { sponges }\end{array}$ & $\begin{array}{l}\text { Dip coating of CNT ink } \\
\text { into polyester fiber } \\
\text { textile }\end{array}$ & $140-160 \mathrm{mAh} \cdot \mathrm{g}^{-1}$ & $0.1 \mathrm{C}$ & $>99.5 \% / 95 \%$ & [52] \\
\hline $\begin{array}{l}\text { 3D multi-layered } \\
\qquad \mathrm{Si} / \mathrm{CNT}\end{array}$ & $\begin{array}{c}\text { Thermal and } \\
\text { plasma-enhanced CVD }\end{array}$ & $\begin{array}{c}2561.2 \mathrm{mAh} \cdot \mathrm{g}^{-1} \\
1.25 \mathrm{mAh} \cdot \mathrm{cm}^{-2} \text { and } \\
595.4 \mathrm{mAh} \cdot \mathrm{cm}^{-3}\end{array}$ & $1 \mathrm{C}$ & $>99 \% / 61 \%$ & [53] \\
\hline $\begin{array}{c}3 \mathrm{D} \\
\text { graphene/ultra-small } \\
\mathrm{SnO}_{2} \text { and } \mathrm{Fe}_{2} \mathrm{O}_{3} \text { anodes }\end{array}$ & $\begin{array}{l}\text { Annealing using } \\
\text { ion-exchange resin and } \\
\text { hydrothermal synthesis }\end{array}$ & $\begin{array}{l}474 \mathrm{mAh} \cdot \mathrm{g}^{-1} \\
\left(\mathrm{SnO}_{2}\right) \text { and } \\
448 \mathrm{mAh} \cdot \mathrm{g}^{-1} \\
\left(\mathrm{Fe}_{2} \mathrm{O}_{3}\right)\end{array}$ & $10 \mathrm{~A} \cdot \mathrm{g}^{-1}$ & $>99.5 \% / 58 \%$ & [54] \\
\hline $\begin{array}{l}\text { 3D nanoporous } \\
\mathrm{Fe}_{2} \mathrm{O}_{3} / \mathrm{Fe}_{3} \mathrm{C}-\text { Graphene } \\
\text { heterogeneous thin films }\end{array}$ & Anodization/CVD & $\begin{array}{l}1650 \mathrm{mAh} \cdot \mathrm{cm}^{-3} \\
\text { and } \sim 518 \mathrm{mAh} \cdot \mathrm{g}^{-1}\end{array}$ & $\sim 6.6 \mathrm{C}$ & $\sim 98 \% / \sim 88 \%$ & [55] \\
\hline $\begin{array}{l}\text { 3D porous architecture } \\
\text { of } \mathrm{Si} / \text { graphene } \\
\text { nanocomposite }\end{array}$ & $\begin{array}{c}\text { Modified sol-gel } \\
\text { method/in situ } \\
\text { magnesiothermic } \\
\text { reduction/spray-drying }\end{array}$ & $\sim 900 \mathrm{mAh} \cdot \mathrm{g}^{-1}$ & $100 \mathrm{~mA} \cdot \mathrm{g}^{-1}$ & $\sim 93 \% / \sim 49 \%$ & [56] \\
\hline $\begin{array}{l}\text { 3D multi-layered } \\
\text { graphene/Si-CuO } \\
\text { quantum dot }\end{array}$ & $\begin{array}{c}\text { Electrophoresis } \\
\text { deposition/annealing }\end{array}$ & $2869 \mathrm{mAh} \cdot \mathrm{g}^{-1}$ & $0.5 \mathrm{C}$ & $>99 \% / 87 \%$ & [57] \\
\hline 3D $\mathrm{TiO}_{2}-$ Graphene-CNT & Solution-based method & $\begin{array}{l}111.2 \mathrm{mAh} \cdot \mathrm{g}^{-1} \\
93.1 \mathrm{mAh} \cdot \mathrm{g}^{-1}\end{array}$ & $\begin{array}{l}10 \mathrm{C} \\
30 \mathrm{C}\end{array}$ & $\sim 98 \% / \mathrm{N} / \mathrm{A}$ & [58] \\
\hline $\begin{array}{l}\text { 3D Li } \mathrm{Ti}_{4} \mathrm{O}_{12} / \text { graphene } \\
\text { foam }\end{array}$ & $\begin{array}{l}\text { CVD and Hydrothermal } \\
\text { Synthesis }\end{array}$ & $160 \mathrm{mAh} \cdot \mathrm{g}^{-1}$ & $30 \mathrm{C}$ & $>99 \% / 98 \%$ & [59] \\
\hline $\begin{array}{l}\text { 3D hierarchical } \\
\text { NiO-graphene }\end{array}$ & $\begin{array}{l}\text { Hydrothermal/a } \\
\text { modified Hummers } \\
\text { method }\end{array}$ & $1065 \mathrm{mAh} \cdot \mathrm{g}^{-1}$ & $200 \mathrm{~mA} \cdot \mathrm{g}^{-1}$ & $97 \% / \sim 65 \%$ & {$[60]$} \\
\hline $\begin{array}{l}\text { 3D graphitic carbon } \\
\text { layer conformally } \\
\text { deposited on perforated } \\
\text { silicon nanowire arrays }\end{array}$ & $\begin{array}{c}\text { Metal-assisted chemical } \\
\text { etching of silicon } \\
\text { wafers/in situ } \\
\text { decomposition } \\
\text { of methane }\end{array}$ & $1500 \mathrm{mAh} \cdot \mathrm{cm}^{-3}$ & $0.2 \mathrm{C}$ & $\sim 99 \% / 78 \%$ & {$[61]$} \\
\hline $\begin{array}{l}\text { 3D porous graphene } \\
\text { networks anchored with } \\
\text { Sn nanoparticles }\end{array}$ & Freeze-drying and CVD & $1089 \mathrm{mAh} \cdot \mathrm{g}^{-1}$ & $0.2 \mathrm{~A} \cdot \mathrm{g}^{-1}$ & $>99 \% / \sim 69 \%$ & {$[62]$} \\
\hline
\end{tabular}


Table 1. Cont

\begin{tabular}{|c|c|c|c|c|c|}
\hline $\begin{array}{l}\text { 3D Carbon-Based } \\
\text { Anode Nanostructure }\end{array}$ & Synthetic Method & Charge Capacity & $\begin{array}{l}\text { C-Rate }(\mathrm{C}) \text { or } \\
\text { Current Density } \\
\left(\mathrm{mA} \cdot \mathrm{g}^{-1}\right)\end{array}$ & $\begin{array}{c}\text { Overall/1st Cycle } \\
\text { Coulombic } \\
\text { Efficiency (\%) }\end{array}$ & Reference \\
\hline $\begin{array}{l}\text { Large-area patterned } \\
\text { 3D CNTs-graphene on } \\
\text { flexible PET film }\end{array}$ & $\begin{array}{l}\text { CVD and sputter } \\
\text { deposition }\end{array}$ & $254 \mathrm{mAh} \cdot \mathrm{g}^{-1}$ & $0.17 \mathrm{C}$ & $>99 \% / \mathrm{N} / \mathrm{A}$ & [63] \\
\hline $\begin{array}{l}\text { 3D monolithic } \\
\mathrm{Fe}_{2} \mathrm{O}_{3} / \text { graphene }\end{array}$ & $\begin{array}{l}\text { Modified } \\
\text { Hummers/Hydrothermal } \\
\text { synthesis/freeze drying }\end{array}$ & $810 \mathrm{mAh} \cdot \mathrm{g}^{-1}$ & $100 \mathrm{~mA} \cdot \mathrm{g}^{-1}$ & $>97 \% / \sim 65 \%$ & [64] \\
\hline $\begin{array}{c}\text { Flexible free-standing } \\
\text { hollow } \mathrm{Fe}_{3} \mathrm{O}_{4} \text { /graphene }\end{array}$ & $\begin{array}{l}\text { Vacuum } \\
\text { filtration/thermal } \\
\text { reduction }\end{array}$ & $\sim 940 \mathrm{mAh} \cdot \mathrm{g}^{-1}$ & $200 \mathrm{~mA} \cdot \mathrm{g}^{-1}$ & $>99.5 \% / \sim 56 \%$ & [65] \\
\hline $\begin{array}{c}\text { Free-standing } \\
\text { layer-by-layer assembled } \\
\text { hybrid graphene- } \mathrm{MnO}_{2} \\
\text { nanotube thin films }\end{array}$ & $\begin{array}{c}\text { Modified } \\
\text { Hummers/Hydrothermal } \\
\text { reaction/ultrafiltration } \\
\text { technique }\end{array}$ & $686 \mathrm{mAh} \cdot \mathrm{g}^{-1}$ & $100 \mathrm{~mA} \cdot \mathrm{g}^{-1}$ & $\sim 99 \% / \sim 56 \%$ & [66] \\
\hline $\begin{array}{l}\text { 3D Sn/graphene } \\
\text { nanocomposite }\end{array}$ & $\begin{array}{l}\text { Modified } \\
\text { Hummers/Chemical } \\
\text { reduction }\end{array}$ & $508 \mathrm{mAh} \cdot \mathrm{g}^{-1}$ & $55 \mathrm{~mA} \cdot \mathrm{g}^{-1}$ & $96.5 \% / \sim 65 \%$ & [67] \\
\hline $\begin{array}{l}\text { 3D ordered mesoporous } \\
\text { carbon }(\mathrm{CMK}-3)\end{array}$ & $\begin{array}{l}\text { Sacrificial silica template } \\
\text { and thermal } \\
\text { carbonization of sucrose }\end{array}$ & $850-1100 \mathrm{mAh} \cdot \mathrm{g}^{-1}$ & $100 \mathrm{~mA} \cdot \mathrm{g}^{-1}$ & $90 \%-93 \% / \sim 35 \%$ & [68] \\
\hline $\begin{array}{c}\text { Hierarchically Porous } \\
\text { Carbon Monoliths with } \\
\text { Highly Ordered } \\
\text { Microstructure }\end{array}$ & $\begin{array}{c}\text { Sacrificial } \\
\text { meso-/macroporous } \\
\text { silica/infiltration/ } \\
\text { carbonization }\end{array}$ & $260 \mathrm{mAh} \cdot \mathrm{g}^{-1}$ & $10 \mathrm{C}$ & $>98 \% / \sim 57 \%$ & [69] \\
\hline $\begin{array}{l}\text { 3D Ordered multimodal } \\
\text { porous carbon (OMPC) }\end{array}$ & $\begin{array}{l}\text { Self-assembly/polymer } \\
\text { infiltration/carbonization/ } \\
\text { silica etching }\end{array}$ & $\begin{array}{l}758 \mathrm{mAh} \cdot \mathrm{g}^{-1} \\
904 \mathrm{mAh} \cdot \mathrm{g}^{-1}\end{array}$ & $\begin{array}{l}100 \mathrm{~mA} \cdot \mathrm{g}^{-1} \\
1000 \mathrm{~mA} \cdot \mathrm{g}^{-1}\end{array}$ & $>98 \% / 57 \%$ & [70] \\
\hline 3D porous carbon/Sn & $\begin{array}{c}\text { Dispersing } \mathrm{SnO}_{2} \\
\text { nanoparticles into a } \\
\text { sacrificial soft-template } \\
\text { polymer } \\
\text { matrix/carbonization }\end{array}$ & $950 \mathrm{mAh} \cdot \mathrm{g}^{-1}$ & $200 \mathrm{~mA} \cdot \mathrm{g}^{-1}$ & $>99.5 \% / 75 \%$ & [71] \\
\hline
\end{tabular}

Note that our proposed 3D carbon nanostructures, methods, and specific capacities are in bold.

Three-dimensional CNTs combined with high-capacity anode materials have been synthesized by various methods; their excellent LIB performance has been demonstrated. Chen et al. fabricated the core/shell anode structure of MWCNT $/ \mathrm{V}_{2} \mathrm{O}_{5}$ sponge using an ALD method. The anode delivered a stable and high areal capacity of $816 \mu \mathrm{Ah} \cdot \mathrm{cm}^{-2}$ at $1 \mathrm{C}\left(1.1 \mathrm{~mA} \cdot \mathrm{cm}^{-2}\right)$; the capacity was 450 times higher than that of its planar $\mathrm{V}_{2} \mathrm{O}_{5}$ thin film counterpart [50]. Hu et al. synthesized a silicon-carbon nanotube coaxial sponge with an areal density of silicon $\left(8 \mathrm{mg} \cdot \mathrm{cm}^{-2}\right)$; additionally, the 3D carbon nanotube was used for an electrical conducting and structural buffering network for high-capacity Si anode materials. The hybrid anode delivered a specific capacity of $1300 \mathrm{mAh} \cdot \mathrm{g}^{-1}$ for 50 cycles with a cutoff voltage of $0.17-1.0 \mathrm{~V}$ at $0.2 \mathrm{C}$ [51]. Hu et al. increased the areal densities of $\mathrm{LiFePO}_{4}$ cathode and $\mathrm{Li}_{4} \mathrm{Ti}_{5} \mathrm{O}_{12}$ anode materials up to $140-170 \mathrm{mg} \cdot \mathrm{cm}^{-2}$; they were approximately seven to eight times higher than the traditional LIB electrode materials. Furthermore, a full cell with both cathode and anode shows a specific capacity of $140-160 \mathrm{mAh} \cdot \mathrm{g}^{-1}$ for 30 cycles at $0.1 \mathrm{C}$ [52]. Q. Xiao et al. created a 3D multi-layered Si/CNT hybrid anode structure by thermal and plasma-enhanced CVD methods. The areal capacity proportionally increased with the number of layers (e.g., $1.25 \mathrm{mAh} \cdot \mathrm{cm}^{-2}$ at four layers); the volumetric capacity of the multilayer $\mathrm{Si} / \mathrm{CNT}$ composite anode was $595.4 \mathrm{mAh} \cdot \mathrm{cm}^{-3}$, superior to the practical volumetric capacity of commercialized graphite anode $\left(\sim 450 \mathrm{mAh} \cdot \mathrm{cm}^{-3}\right)$; moreover, its theoretical volumetric capacity is $830 \mathrm{mAh} \cdot \mathrm{cm}^{-3}$ [53].

Three-dimensional graphene has been incorporated with high-capacity anode materials through various methods, thus leading to outstanding LIB performance. Li et al. synthesized the 3D graphene/ultra-small $\mathrm{SnO}_{2}$ and $\mathrm{Fe}_{2} \mathrm{O}_{3}$ anodes by a two-step method: annealing using ion-exchange resin and then a hydrothermal process. Specific capacities of $474 \mathrm{mAh} \cdot \mathrm{g}^{-1}$ and $448 \mathrm{mAh} \cdot \mathrm{g}^{-1}$ were obtained for $\mathrm{SnO}_{2}$ - and $\mathrm{Fe}_{2} \mathrm{O}_{3}$-based anodes, respectively, at $10 \mathrm{~A} \cdot \mathrm{g}^{-1}$ for 1000 cycles; these values were 
superior to those of most recently reported $\mathrm{SnO}_{2}$ - and $\mathrm{Fe}_{2} \mathrm{O}_{3}$-based graphene composite anodes [54]. Yang et al. fabricated 3D nanoporous $\mathrm{Fe}_{2} \mathrm{O}_{3} / \mathrm{Fe}_{3} \mathrm{C}$-graphene heterogeneous thin films by anodization and chemical vapor deposition (CVD) methods, in which multi-layer graphene coated on the 3D thin films served as an electrical conducting agent. The 3D thin film anode showed volumetric and specific capacities of $1650 \mathrm{mAh} \cdot \mathrm{cm}^{-3}$ and $\sim 518 \mathrm{mAh} \cdot \mathrm{g}^{-1}$ at $\sim 6.6 \mathrm{C}$ for 1000 cycles, respectively. This anode also showed volumetric and gravimetric energy densities of $2.94 \mathrm{Wh} \cdot \mathrm{cm}^{-3}$ and $\sim 924 \mathrm{Wh} \cdot \mathrm{kg}^{-1}$, respectively, and volumetric and gravimetric power densities of $5.84 \mathrm{~W} \cdot \mathrm{cm}^{-3}$ and $\sim 1834 \mathrm{~W} \cdot \mathrm{kg}^{-1}$, respectively [55]. $\mathrm{Wu}$ et al. prepared porous silicon spheres enclosed by 3D graphene network by using a two-step method of layer-by-layer assembly and in situ magnesiothermic reduction [56]. In their report, the 3D Si-graphene hybrid anode delivered a 300\% higher specific capacity $\left(\sim 1300 \mathrm{mAh} \cdot \mathrm{g}^{-1}\right)$ than that of a bare silicon sphere-based anode at $0.05 \mathrm{C}$ after 25 cycles. Baskaran et al. synthesized 3D multi-layered graphene/ $\mathrm{Si}-\mathrm{CuO}$ quantum dot anodes by electrophoresis deposition, within which graphene mainly functions as an electrical conducting network for the anode. Furthermore, $\mathrm{Cu}_{3} \mathrm{Si}$ is formed by the subsequent annealing process; consequently, $\mathrm{CuO}-\mathrm{Cu}_{3} \mathrm{Si}$ serves as a mechanical cushion against the large-volume expansion/contraction of Si during cycling. The composite anode delivers a five-fold higher specific capacity $\left(2869 \mathrm{mAh} \cdot \mathrm{g}^{-1}\right)$ than that of graphene for an initial cycle at 0.5C [57]. Shen et al. fabricated $3 \mathrm{D} \mathrm{TiO}_{2}$-graphene-CNT composite anode materials through controlled hydrolysis of tetrabutyl titanate (TBT), in which the CNTs act as an electrically conducting network to facilitate electron transport between the $\mathrm{TiO}_{2}$-anchored graphene layers. Furthermore, CNTs served as mechanical bridges between the graphene layers, which prevented their restack problems, thus leading to the preservation of their high surface area and accelerating the $\mathrm{Li}^{+}$ion insertion/extraction rate into/from the 3D anode structure. The 3D anode showed a capacity of $93.1 \mathrm{mAh} \cdot \mathrm{g}^{-1}$ at $30 \mathrm{C}$ (this value is higher than that of the previously reported graphene- $\mathrm{TiO}_{2}$ hybrid anode materials) and $111.2 \mathrm{mAh} \cdot \mathrm{g}^{-1}$ at $10 \mathrm{C}$ after 100 cycles, respectively [58]. Li et al. employed 3D flexible, conducting network of graphene foam loaded with $\mathrm{Li}_{4} \mathrm{Ti}_{5} \mathrm{O}_{12}$ and $\mathrm{LiFePO}_{4}$ as anode and cathode materials, respectively, by using hydrothermal synthetic method. The 3D electrode-based flexible full LIB was cycled over 100 cycles at $10 \mathrm{C}$ with only $4 \%$ capacity loss $\left(117 \mathrm{mAh} \cdot \mathrm{g}^{-1}\right)$ and this value surpasses most full LIBs reported in terms of rate capability and cycling performance [59]. Tao et al. employed a sonication method to anchor carnation-like $\mathrm{NiO}$ fabricated via a hydrothermal method both onto and into graphene layers by using a modified Hummers method. The 3D hierarchical NiO-graphene hybrid anode exhibited a reversible capacity of $1065 \mathrm{mAh} \cdot \mathrm{g}^{-1}$ (higher than the theoretical capacity of $\mathrm{NiO}$ $\left.\left(718 \mathrm{mAh} \cdot \mathrm{g}^{-1}\right)\right)$ for the 50 th cycle at a current density of $200 \mathrm{~mA} \cdot \mathrm{g}^{-1}$. Graphene layers largely served as electrical conducting pathways to reduce the polarization of the anode; consequently, they decrease the internal resistance of an LIB cell. Furthermore, graphene layers effectively circumvented the issue with the physical aggregation of $\mathrm{NiO}$ by maintaining a steadfast cycling performance and rate capability [60]. As mentioned earlier, 3D carbon nanostructures were employed to create large volumetric and areal capacities for large-scale energy storage systems demanding high values of volumetric and gravimetric energy densities. With respect to other anode configurations, a 3D silicon-carbon composite anode is considered a significant contender to achieve the aforementioned aim. Wang et al. synthesized the 3D graphitic carbon layer conformally deposited on perforated silicon nanowire arrays through a metal-aided chemical etching of silicon wafers and in situ decomposition of methane $\left(\mathrm{CH}_{4}\right)$ for depositing carbon. Noticeably, they struck a balance between the maximized bulk density of Si nanowires and the necessary porous structures to guard against the strain induced by a large-volume variation $(\sim 300 \%)$ of Si despite their trade-off relationship. Furthermore, the 3D anode structure exhibited its structural and interfacial stability by maintaining a volumetric capacity of $1500 \mathrm{mAh} \cdot \mathrm{cm}^{-3}$ after 200 cycles; this value was nearly four times higher than those of commercially available graphite and comparable to or even superior to the other reported values of Si-based anodes [61].

Three-dimensional hierarchical nanoporous carbon possesses its exceptional surface area and pore volume to offer more $\mathrm{Li}^{+}$ion accommodation sites relative to the other carbon nanomaterials. Zhou et al. fabricated 3D ordered mesoporous carbon (CMK-3) with a uniform pore size of $3.9 \mathrm{~nm}$, 
a Brunauer-Emmer-Teller (BET) surface area of $1030 \mathrm{~m}^{2} \cdot \mathrm{g}^{-1}$, and a total pore volume of $0.87 \mathrm{~cm}^{3} \cdot \mathrm{g}^{-1}$ by using a sacrificial silica template and thermal carbonization of sucrose. Thanks to the unique nanoscale pore structures leading to such high surface area and pore volume, high capacity was obtained in the range of $850-1100 \mathrm{mAh} \cdot \mathrm{g}^{-1}$ at a current density of $100 \mathrm{~mA} \cdot \mathrm{g}^{-1}$ [68]. Hu et al. utilized a sacrificial meso-/macroporous silica-based hard template for the fabrication of a 3D porous carbon replica via the infiltration of the silica template into a mesophase pitch dissolved solution and the subsequent thermal carbonization and silica removal. The 3D porous carbon, consisting of well-interconnected walls with submicron thickness, offers a porosity large enough to maintain a sufficient $\mathrm{Li}^{+}$diffusion rate while maintaining high electrical conductivity of $\sim 0.1 \mathrm{~S} \cdot \mathrm{cm}^{-1}$; thus, 3D porous carbon can be directly responsible for a high C-rate capability of the 3D carbon anode (e.g., $260 \mathrm{mAh} \cdot \mathrm{g}^{-1}$ at 10C) [69]. Fang et al. synthesized 3D ordered multimodal porous carbon (OMPC) through the self-assembly of polystylene (PS)/silica nanoparticles as a sacrificial template and the polymer infiltration of furfurylalcohol (FFA) as a carbon precursor, followed by carbonization and silica etching. The OMPC exhibited a large BET surface area of $1120 \mathrm{~m}^{2} \cdot \mathrm{g}^{-1}$ and a total pore volume of $2.36 \mathrm{~cm}^{3} \cdot \mathrm{g}^{-1}$. The excellent cycling performance of OMPC is mainly due to the unique hierarchical porosity, comprising a well-tailored 3D interconnected, ordered macropore framework, which exhibits open mesopores facilitating mass transport and suppressing the volume variation during cycling. OMPC delivered a specific capacity of $904 \mathrm{mAh} \cdot \mathrm{g}^{-1}$ at a specific current density of $100 \mathrm{~mA} \cdot \mathrm{g}^{-1}, 127 \%$ greater than CMK-3 (no well-defined hierarchical nanostructure, $714 \mathrm{mAh} \cdot \mathrm{g}^{-1}$ ), while the OMPC delivered a specific capacity of $758 \mathrm{mAh} \cdot \mathrm{g}^{-1}, 161 \%$ greater than CMK-3 $\left(472 \mathrm{mAh} \cdot \mathrm{g}^{-1}\right)$ at $1000 \mathrm{~mA} \cdot \mathrm{g}^{-1}$ [70]. Xu et al. prepared a porous carbon/Sn anode by dispersing $\mathrm{SnO}_{2}$ nanoparticles into a sacrificial soft-template polymer matrix (as a porous structure mold) accompanied by subsequent carbonization. The porous carbon offered high electrical conductivity and served as a structural buffer to avoid the pulverization induced by large volume variation of $\mathrm{Sn}$, in conjunction with the large surface area for the facile electron and $\mathrm{Li}^{+}$ion charge transfers. Thanks to these traits, the 3D porous carbon/Sn anode delivered a high specific capacity of $950 \mathrm{mAh} \cdot \mathrm{g}^{-1}$ at $200 \mathrm{~mA} \cdot \mathrm{g}^{-1}$; the anode showed a high rate capability, verified by a capacity of $360 \mathrm{mAh} \cdot \mathrm{g}^{-1}$ even at a high current density of $2000 \mathrm{~mA} \cdot \mathrm{g}^{-1}$ [71].

The overall Coulombic Efficiency (CE) of the 3D carbon-based anode nanostructures listed in Table 1 shows an average value of $98 \%$; however, an average $\mathrm{CE}$ obtained from the first cycle is $69 \%$. The lower CE value in the first cycle is mainly associated with the formation of solid electrolyte interphase (SEI) with the large surface area of anode nanostructures. It is important to note that the low CE during the first cycle is not limited to 3D structures; that is, any nanostructured materials are susceptible to the irreversible capacity occurring in the first cycle. To solve the problem associated with high irreversible capacity during the first cycle, four main strategies have been implemented [72]: (1) oxidation of the graphite prismatic surface [73,74]; (2) deposition of inorganic materials and particles on the graphite particle's surface [75-77]; (3) the modification of the surface of graphite anode [78-81]; and (4) incorporation of carbonaceous coatings [82-84]. Those modified electrodes have shown high $\mathrm{CE}$ in the first cycle (up to 95\%). As mentioned in Table 1, the highest Coulombic efficiencies for the first cycle were demonstrated with $\mathrm{Li}_{4} \mathrm{Ti}_{5} \mathrm{O}_{12}$ and $\mathrm{RuO}_{2}$ anode materials $[43,52,59]$. In addition, several coating methods applied to nanocarbon-based materials have shown promising results: Ren et al. pretreated a surface of $\mathrm{Mn}_{3} \mathrm{O}_{4} /$ reduced graphite oxide with polypyrrole, which resulted in a CE of $65 \%$ for the first cycle [85]; Fu et al. demonstrated a CE of $76 \%$ for the first cycle by coating carbon on a silicon/carbon nanofiber composite [86]; and Wang et al. deposited $\mathrm{SiO}_{\mathrm{x}}$ on the surface of nanoporous carbon in order to enhance the first cycle CE (up to 83\%) [87].

\section{3D Carbon-Nanostructured Electrodes: Published Results}

\subsection{Fabrication of $3 D C N T s$}

A 3D metal substrate as a current collector is beneficial for increasing the surface area of CNTs, consequently leading to a higher amount of $\mathrm{Li}^{+}$ion intake into their structure, relative to its $2 \mathrm{D}$ 
counterpart [33]. Accordingly, we expect to attain superior electrochemical properties for advanced LIBs from 3D CNTs compared to the conventional 2D CNTs. Driven by this motivation, here we introduce a 3D interwoven $\mathrm{Cu}$ mesh as a substrate for the direct growth of CNTs. In this study, CNTs were grown on 3D Cu by a two-step method including sputtering for the deposition of catalytic thin layer ( $\mathrm{Ni}$ and $\mathrm{Ti}$ ) and thermal CVD. Figure 2a demonstrates the simple layout of magnetron sputtering system, where the main chamber is evacuated at a high vacuum of $\sim 1 \times 10^{-7}$ Torr, with a sputtering gun and substrate holder serving as cathode and anode, respectively.
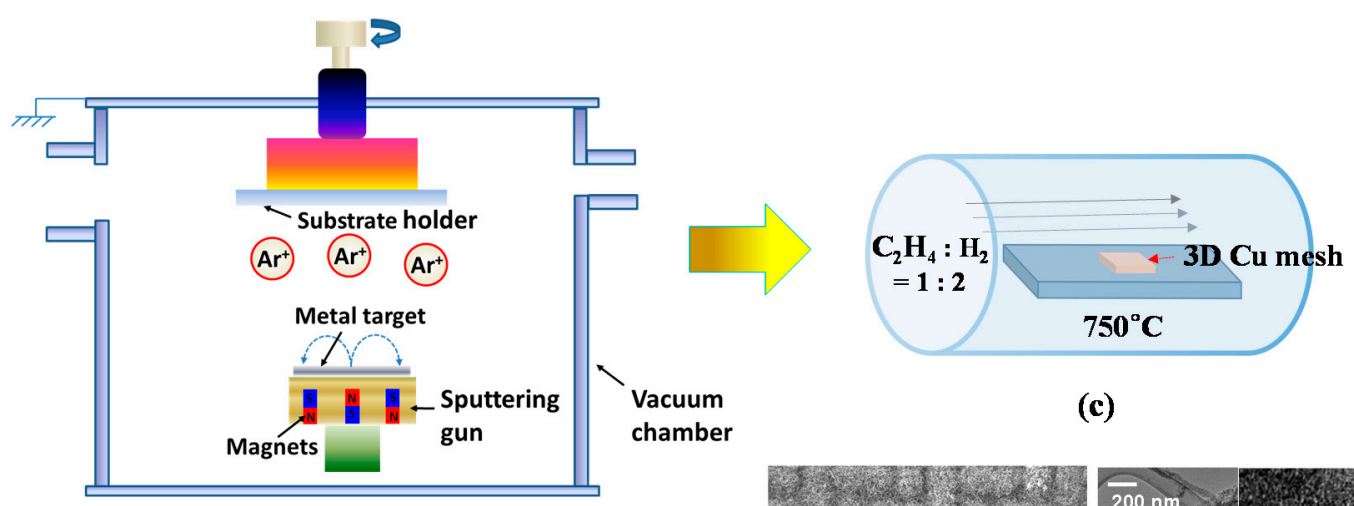

(c)

(a)

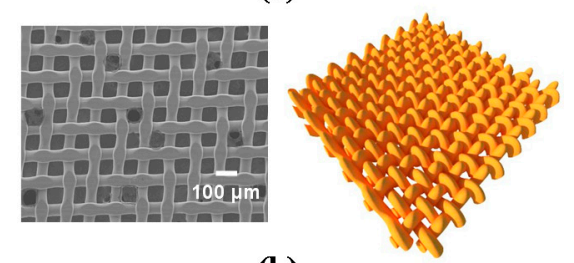

(b)
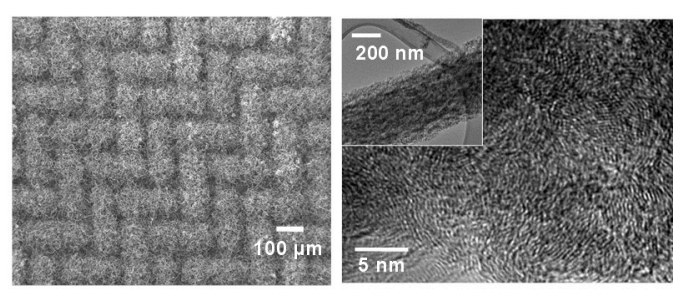

(d)

Figure 2. (a) Schematic diagram of a magnetron sputtering system for Ti and Ni deposition; (b) scanning electron microscopy (SEM) image and schematic diagram of 3D Cu mesh; (c) schematic diagram of a CVD for CNT growth; (d) SEM image of 3D CNTs on Cu (left) and high-resolution transmission electron microscopy (HRTEM) image of a single CNT with low-ordered graphitization structure (right) (Reprinted with permission from [88]. Copyright (2015) Elsevier.).

For CNT growth, Ni was chosen as a catalytic metal and Ti as a diffusion barrier to prevent the formation of a $\mathrm{Cu}-\mathrm{Ni}$ solid solution. The sputtering process involved plasma generation by Ar gas ( 10 standard cubic centimeters per minute (SCCM)) at a power of $\sim 75 \mathrm{~W}$ under a processing pressure of $\sim 5 \mathrm{mTorr}$ to deposit the uniform thin films of $\mathrm{Ti}$ and $\mathrm{Ni}$ on $\mathrm{Cu}$ mesh. After deposition of the thin films, $\mathrm{Cu}$ mesh/Ti $(\sim 10 \mathrm{~nm}) / \mathrm{Ni}(\sim 2.5-10 \mathrm{~nm})$ layers were obtained. The Ti/Ni thin films were presumably nucleated and grown in an island (or Volmer-Weber) growth mode since the species (in our case, $\mathrm{Ni}$ atoms) are more strongly bonded to each other than to the substrate. Subsequently, these species lead to the coalescence of islands, thus forming a continuous film [89]. Figure $2 b$ (left and right) represents a plane-view scanning electron microscopy (SEM) image of a 3D Cu mesh compressed at a pressure of 5000 bar along with the schematic of interwoven $\mathrm{Cu}$ wires of the mesh (200 Mesh Copper, TWP, Inc., Berkeley, CA, USA). Furthermore, CNTs have been grown by the chemical vapor deposition (CVD) technique, which has also been extensively employed to synthesize carbon nanomaterials such as carbon fibers, filaments, and nanotube materials for the past two to three decades [90]. Figure $2 \mathrm{c}$ shows a schematic diagram of a CVD reactor for CNT growth. The proposed model as depicted by Baker et al. explains the nucleation and growth mechanism of 3D CNTs on $\mathrm{Cu}$ in the following steps [91]: (1) a Ni thin layer could begin agglomerating as separate, spherical cap-shaped $\mathrm{Ni}$ islands (with an average size of $129 \mathrm{~nm}$ in Figure $1 \mathrm{~b}$ (bottom)) due to thermal diffusion of $\mathrm{Ni}$ atoms at $\sim 700{ }^{\circ} \mathrm{C}$; (2) a carbon precursor gas (in our case, ethylene $\left.\left(\mathrm{C}_{2} \mathrm{H}_{4}\right)\right)$ is introduced into the CVD chamber, decomposed into 
carbon atoms, and diffused into the Ni islands from their surface to the core due to the thermal gradient in the Ni islands; (3) the carbon dissolves into the Ni islands until its optimum solubility limit and then precipitates below the end of Ni islands, promoting the growth of CNTs in the desired time frame. Figure $2 \mathrm{~d}$ (left) shows the field emission scanning electron microscopy (FESEM) image of the as-grown 3D CNTs on $\mathrm{Cu}$, highlighting densely packed and randomly oriented CNTs. The CNTs also show a low-ordered graphitization structure, revealed by a high-resolution transmission electron microscopy (HRTEM) (In Figure 2d (right), the inset shows a single CNT with an average diameter of $250 \mathrm{~nm}$ ).

\subsection{D CNT Growth}

The morphology (e.g., length and diameter) of high-quality CNTs would be largely responsible for enhanced electrochemical properties of novel 3D CNT-based anodes comprising pure CNTs or hybrid nanomaterials (e.g., nanoscale silicon-CNTs and graphene-CNTs) for advanced LIBs [5]. To optimize the morphology of the CNTs, our team investigated the morphological variation of CNTs with growth condition (temperature and time) and the thickness of Ni catalysts (Table 2).

Table 2. The morphology variation of 3D CNTs on $\mathrm{Cu}$ with the different growth conditions of temperature and time for carbon decomposition, and the thickness of sputter-coated Ni thin film. Note that the scale bar applies to all the images.

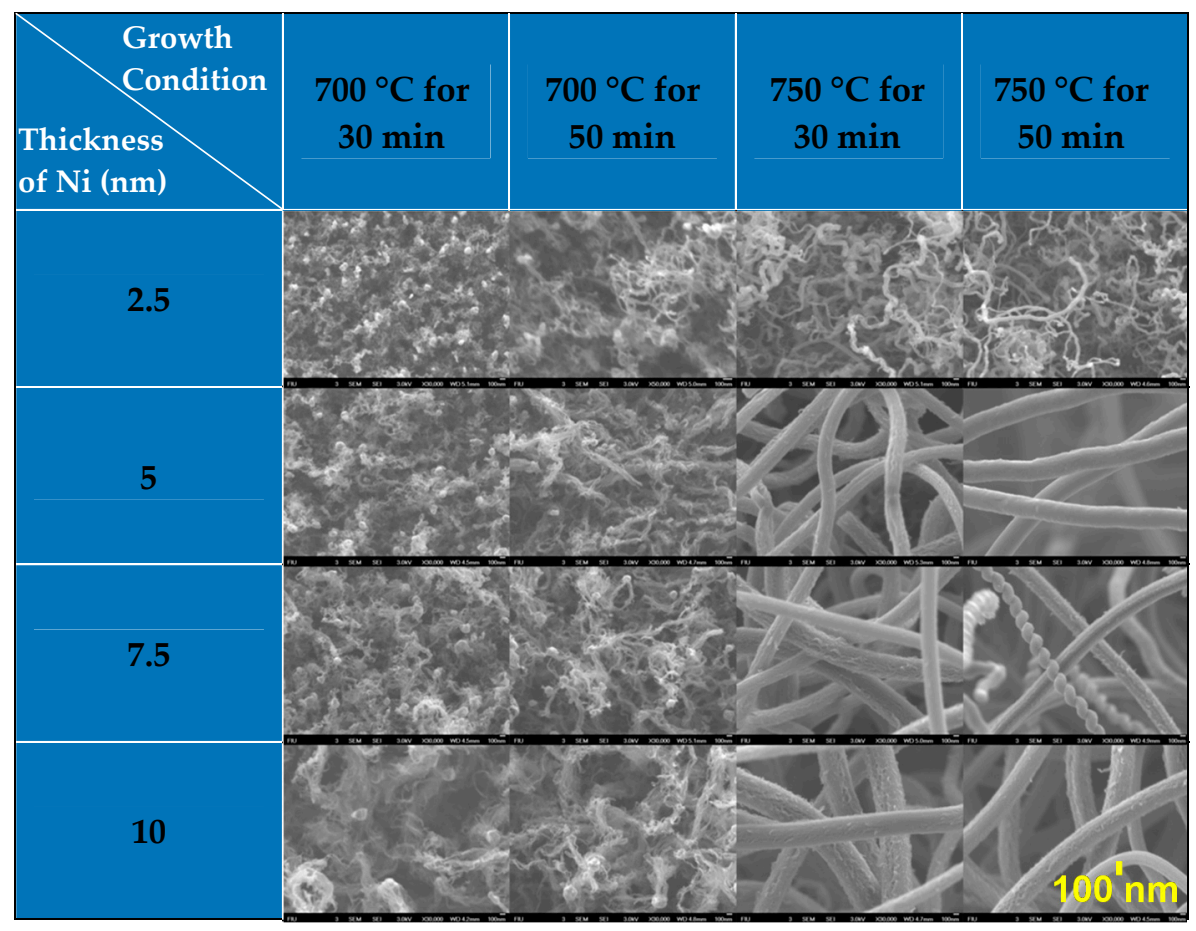

The rate of decomposition and diffusion of carbon into $\mathrm{Ni}$ atoms increased with an elevation in temperature, thus leading to the higher growth rate of CNTs [89,92]. In Figure 3a, the average agglomerated sizes (mean values) of Ni islands also increased from 32 to $74 \mathrm{~nm}$ (231\%) with elevated temperature from 700 to $750{ }^{\circ} \mathrm{C}$ at $2.5 \mathrm{~nm}$ in the $\mathrm{Ni}$ thickness, and a similar trend is followed for the other cases of 5,7.5, and $10 \mathrm{~nm}$; this is largely attributed to the increased thermal diffusion of $\mathrm{Ni}$ atoms at an elevated temperature. The resulting large surface area of the Ni islands offers more sites for carbon adsorption, manifesting proper diffusion channels due to the large concentration gradient of carbon across the surface [89,92]. Empirically, an average diameter of CNTs (less than $100 \mathrm{~nm}$ ) resulted from conditions with a growth temperature of $700{ }^{\circ} \mathrm{C}$, a growth time of $50 \mathrm{~min}$, and $10 \mathrm{~nm}$ thick Ni thin layer, whereas an average diameter of CNTs (200-300 nm) was obtained with an increased temperature of $750{ }^{\circ} \mathrm{C}$ at conditions with the same growth time and Ni thickness. 
Noticeably, a considerable increase in the average CNT diameter from 50 to $250 \mathrm{~nm}$ was obtained by increasing the Ni thickness from 2.5 to $5 \mathrm{~nm}$ at $750{ }^{\circ} \mathrm{C}$. The areal density of CNTs was correspondingly augmented from less than $0.2 \mathrm{mg} \cdot \mathrm{cm}^{-2}$ to greater than $2.2 \mathrm{mg} \cdot \mathrm{cm}^{-2}$ for the growth time of $50 \mathrm{~min}$. Furthermore, the areal density was increased from $1.3 \mathrm{mg} \cdot \mathrm{cm}^{-2}$ to $2.8 \mathrm{mg} \cdot \mathrm{cm}^{-2}$ (by $215 \%$ ) when the growth time increased from 30 to 50 min under the conditions of $750{ }^{\circ} \mathrm{C}$ and $10 \mathrm{~nm}$ thick Ni. The degree of CNT crystallinity was investigated by considering two different diameters of 50 and $250 \mathrm{~nm}$ by using Raman spectroscopy analysis. The two samples were designated by S-CNT (the smaller diameter CNTs were grown by $2.5 \mathrm{~nm}$ thick Ni at a growth temperature of $750{ }^{\circ} \mathrm{C}$ ) and L-CNT (the larger diameter $\mathrm{CNTs}$ were grown by $10 \mathrm{~nm}$ thick Ni at $750{ }^{\circ} \mathrm{C}$ ), respectively (the morphologies of both S-CNT and L-CNT are shown in Table 2). Both S-CNT and L-CNT exhibited a similar peak ratio $\left(\mathrm{I}_{\mathrm{D}} / \mathrm{I}_{\mathrm{G}}\right)$ (nearly 0.9$)$ of D-band $\left(\sim 1350 \mathrm{~cm}^{-1}\right)$ to G-band $\left(\sim 1580 \mathrm{~cm}^{-1}\right)$, serving as fingerprints of disorder and $\mathrm{sp}^{2}$ graphene arrangement in the CNTs, respectively (Figure $3 \mathrm{~b}$ ). This result clarified that CNTs with a low degree of crystallinity can be grown at lower temperatures $\left(700-750{ }^{\circ} \mathrm{C}\right.$ in our study), relative to the graphitization temperature $\left(2600-3300^{\circ} \mathrm{C}\right)$. The low-degree crystalline CNTs are beneficial for facilitating the insertion and extraction of $\mathrm{Li}^{+}$ions into and from the CNTs through the defects and the preferentially oriented graphene layers on the CNT surfaces $[93,94]$

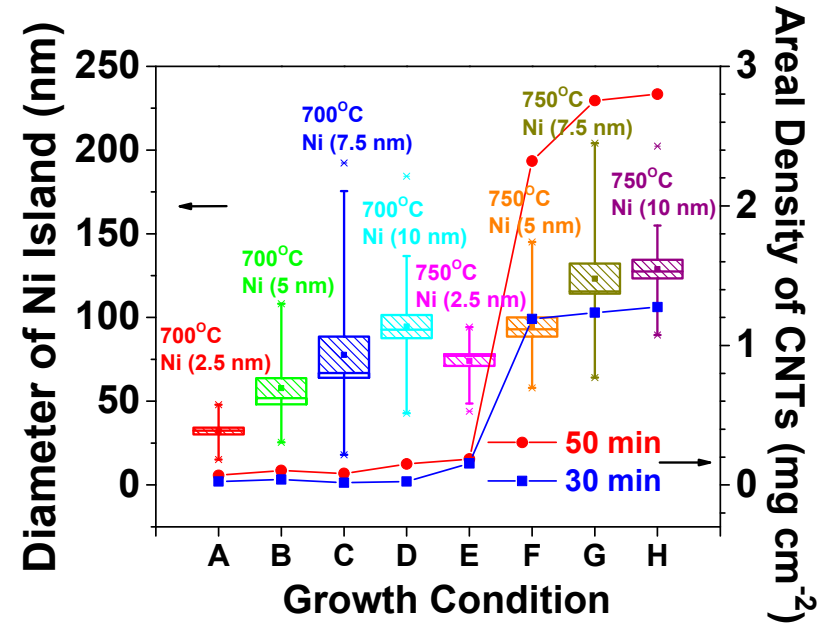

(a)

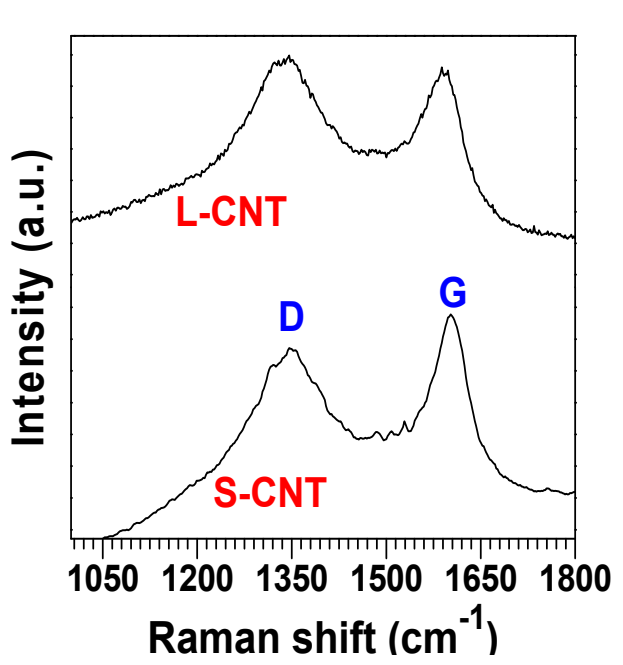

(b)

Figure 3. (a) The variations of Ni island size and CNTs' areal density with CNT growth conditions: temperature and the thickness of sputter-coated Ni thin film; (b) Raman spectra to compare the degree of crystalline order of 3D CNTs synthesized at the two different growth conditions.

\subsection{D Multi-Layered CNTs}

Most of the nanocarbon-based anode materials have suffered from low mass loading and bulk density, which could hamper their practical applications in large-scale energy storage systems demanding high areal and volumetric capacity [29]. One legitimate strategy to overcome these hurdles is to design a multi-layered 3D CNT structure that efficiently increases its areal and bulk density. A multi-layered 3D CNT-based anode structure was fabricated by following the procedures outlined in Figure 4a-d. Bulk density of the compressed CNT layers was needed to obtain their volumetric capacity, determined by their thickness and footprint areas measured by a digital caliper (VWR). For comparison, untreated control multi-layered CNTs were also assembled at room temperature using a precision press (MTI Inc., Salt Lake City, UT, USA) with a minor pressure of 6 bar and without using the binder. 
(I)

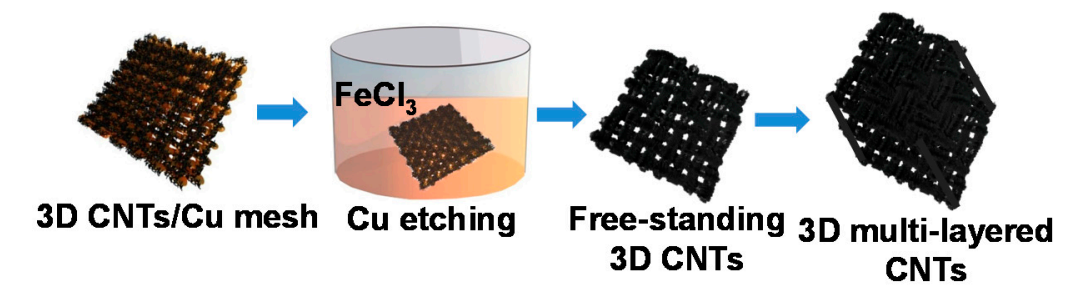

(a)

(b)

(c)

(d)
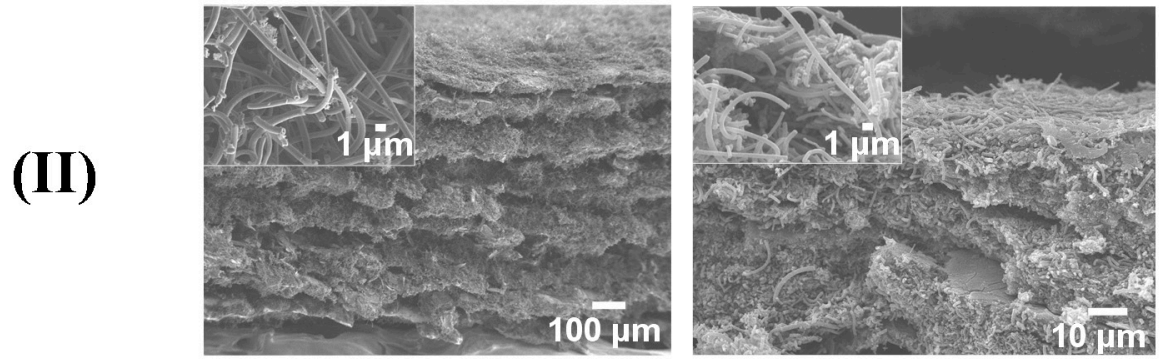

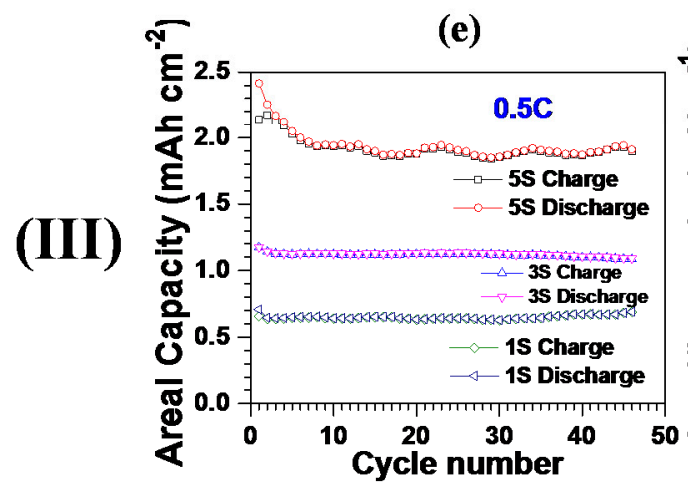

(g)

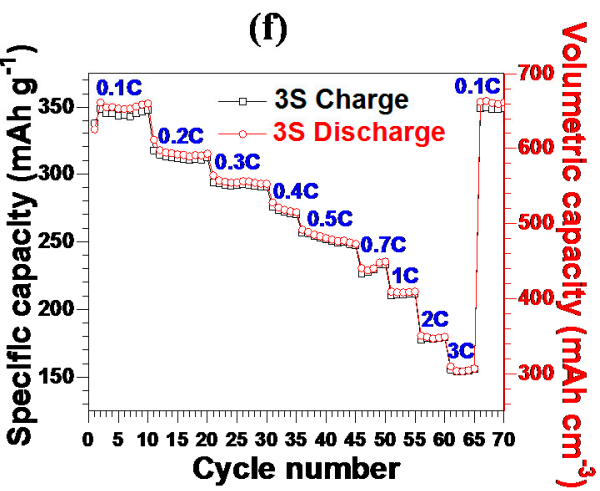

(h)

Figure 4. (I) Procedures for the synthesis of multi-layered 3D CNT anode: (a) 3D CNTs grown on Cu via CVD; (b) $\mathrm{Cu}$ removal by $\mathrm{FeCl}_{3}$ etching solution; (c) 3D free-standing CNT structure after washing away $\mathrm{Cu}$; (d) the multi-layered 3D CNTs by PVDF binder-assisted pressing of the layers of 3D CNTs. (II) Field emission scanning electron microscopy (FESEM) cross-sectional images of the structures of multi-layered 3D CNTs obtained (e) before and (f) after the treatment of binder and high compressive pressure at $60^{\circ} \mathrm{C}$. (III) Comparative electrochemical properties of the multi-layered 3D CNT anodes with the number of stacked layers. Note that $1 S, 35$, and $5 S$ of CNTs have areal densities of 2.6, 4.5, and $9.0 \mathrm{mg} \cdot \mathrm{cm}^{-2}$ and bulk densities of $1.3,1.85$, and $1.8 \mathrm{~g} \cdot \mathrm{cm}^{-3}$, respectively. (g) Areal capacity versus cycle number of all the multi-layered 3D CNT anodes at $0.5 \mathrm{C}$; (h) specific and volumetric capacities of $3 \mathrm{~S}$ versus cycle number at various C-rates (Reprinted with permission from [88]. Copyright (2015) Elsevier.).

Figure 4e exhibits the multi-layered 3D CNTs with a low pressure of 6 bar. The overall thickness measured for this structure was $780 \mu \mathrm{m}$, delivering areal and bulk densities of $34.9 \mathrm{mg} \cdot \mathrm{cm}^{-2}$ and $0.45 \mathrm{~g} \cdot \mathrm{cm}^{-3}$, respectively. Such an exceptional areal density was nearly threefold higher than commercially available graphite anodes [95]. As expected, the miniscule applied pressure had no impact on the structural damage of the CNTs (inset of Figure 4e). To further increase the CNTs' density, polyvinylidene fluoride (PVDF) is employed as a binder, followed by a hot press (detailed procedures were mentioned above). The compressed multi-layered CNTs reduced their overall thickness down to $\sim 50 \mu \mathrm{m}$, augmenting the bulk density up to $1.8 \mathrm{~g} \cdot \mathrm{cm}^{-3}$ (Figure $4 \mathrm{f}$ ). The denser CNT structure obtained by the hot press is seen in the close-up SEM image (inset of Figure 4f). The bulk densities for the three different multi-layered CNTs denoted by $1 \mathrm{~S}$ (one layer), 3S (three layers), and $5 \mathrm{~S}$ (five layers) were recorded to be $1.3,1.85$, and $1.8 \mathrm{~g} \cdot \mathrm{cm}^{-3}$, respectively.

Figure $4 \mathrm{~g}$ shows the areal capacity behavior as a function of cycle number, highlighting the linear increase in areal capacity with the layer number of CNTs. As expected, $5 \mathrm{~S}$ yields an average 
areal capacity of $1.92 \mathrm{mAh} \cdot \mathrm{cm}^{-2}$, sufficient for commercial requirements, which is $173 \%$ and $275 \%$ superior to $3 S$ and 1S, respectively [96]. Such a proportional increment of areal capacity suggests that assembling multi-layered CNTs will be a legitimate tactic for increasing the loading content of carbon nanomaterials and improving relevant areal capacity. Augmenting bulk density, obtained by compressing multi-layered CNTs, will lead to their enhanced volumetric capacity, a key parameter for the utilization of carbon nanomaterials in scaling up next-generation LIBs. The specific and volumetric capacities decreased stepwise with an increase in C-rate from $0.1 \mathrm{C}$ to $3 \mathrm{C}$, which is mainly due to lowering the ionic conductivity of electrolytes with elevated C-rates [97]. The reversible capacities are recorded as $312 \mathrm{mAh} \cdot \mathrm{g}^{-1}\left(578 \mathrm{mAh} \cdot \mathrm{cm}^{-3}\right), 251 \mathrm{mAh} \cdot \mathrm{g}^{-1}\left(465 \mathrm{mAh} \cdot \mathrm{cm}^{-3}\right), 211 \mathrm{mAh} \cdot \mathrm{g}^{-1}\left(390 \mathrm{mAh} \cdot \mathrm{cm}^{-3}\right)$, and $155 \mathrm{mAh} \cdot \mathrm{g}^{-1}\left(287 \mathrm{mAh} \cdot \mathrm{cm}^{-3}\right)$ at $0.2 \mathrm{C}, 0.5 \mathrm{C}, 1 \mathrm{C}$, and 3C, respectively. Furthermore, the capacity at $0.1 \mathrm{C}$ was rehabilitated to the initial value at the same $\mathrm{C}$-rate after undergoing a C-rate test up to $3 \mathrm{C}$, presumably highlighting the well-preserved structural integrity of $3 \mathrm{~S}$. The volumetric capacities of multi-layered 3D CNT anodes exceeded the recently published CNTs (48 $\mathrm{mAh} \cdot \mathrm{cm}^{-3}$ [98] and $395 \mathrm{mAh} \cdot \mathrm{cm}^{-3}$ [99]), porous graphite $\left(463 \mathrm{mAh} \cdot \mathrm{cm}^{-3}\right)$ [100] and commercial-grade graphitized mesocarbons (301.5 $\mathrm{mAh} \cdot \mathrm{cm}^{-3}$ ) [32]. With such excellent electrochemical properties, our proposed multi-layered CNT-based anodes can be envisioned to pave the way for the implementation of carbon nanomaterials to advanced LIBs demanding high volumetric capacity.

\subsection{D CNT-Based Flexible LIB}

Recent developments into flexible electronic devices have pioneered the key technologies in large-scale advanced flexible LIBs as a main power source [101]. Inspired by this technological progress, we designed a 3D free-standing CNT anode incorporated into a flexible LIB cell without compromising the areal and volumetric capacities. Figure $5 \mathrm{a}, \mathrm{b}$ shows the schematic diagrams and digital image of our proposed flexible LIB cell to highlight each of its components. The as-grown 3D CNTs were transferred onto a graphene/PET film, thus acting as a working electrode (refer to Section 3.7 for brief procedures of graphene growth on $\mathrm{Cu}$; refer to $[63,102]$ for the process behind the subsequent transfer of graphene onto a polyethylene terephthalate (PET) film), while lithium metal adhered to a PET film was used for the reference and counter electrodes. In this assembly, no metal (e.g., $\mathrm{Cu}$ and $\mathrm{Al}$ ) foils were used as a current collector for either cathode or anode in the flexible cell; as a result, this would allow for conformal contact between electroactive materials and metals. An assembled flexible LIB cell is represented by a schematic diagram and digital image (Figure 5). The open circuit voltage (OCV) of the flexible battery was recorded by a digital multi-tester. The charge (delithiation) and discharge (lithiation) cycles of the assembled cell with the 3D CNT-based anode were performed by using a battery-testing unit at room temperature at a C-rate of $0.1 \mathrm{C}$ in the cut-off voltage ranging from 0.01 to $3.0 \mathrm{~V}$. The bulk density of 3D CNTs in the assembled cell was determined by their overall thickness via a digital caliper (VWR), thus obtaining volumetric capacity. A 3D CNT-based flexible LIB cell was subjected to electrochemical characterization with its relatively low total weight of $\sim 65 \mathrm{mg}$ and electroactive area of approximately $1 \mathrm{~cm} \times 1 \mathrm{~cm}$, although there is difficulty in comparing this cell with others due to a lack of standardization. Figure $5 c$ demonstrates an areal capacity of the cell $\left(\sim 0.25 \mathrm{mAh} \cdot \mathrm{cm}^{-2}\right)$ at $0.1 \mathrm{C}$, exceeding other flexible LIBs incorporated with graphene-based materials $[103,104]$. Moreover, the cell delivered a high volumetric capacity of $\sim 300 \mathrm{mAh} \cdot \mathrm{cm}^{-3}$ at $0.1 \mathrm{C}$, acquired from a bulk density $\left(1.45 \mathrm{~g} \cdot \mathrm{cm}^{-3}\right)$ and a specific capacity $\left(207 \mathrm{mAh} \cdot \mathrm{g}^{-1}\right)$ of the 3D CNTs. The capacity fading exhibited in the cell during cycling (Figure $5 c$ ) could be due to insufficient packaging of the LIB cell; the commercial packaging process could be a possible remedy for this shortcoming. Furthermore, nearly steady OCV values ( $2.55 \mathrm{~V}$ (flat) $\sim 2.75 \mathrm{~V}$ ( $90^{\circ}$ bending)) were recorded under deformed conditions (Figure 5d). 


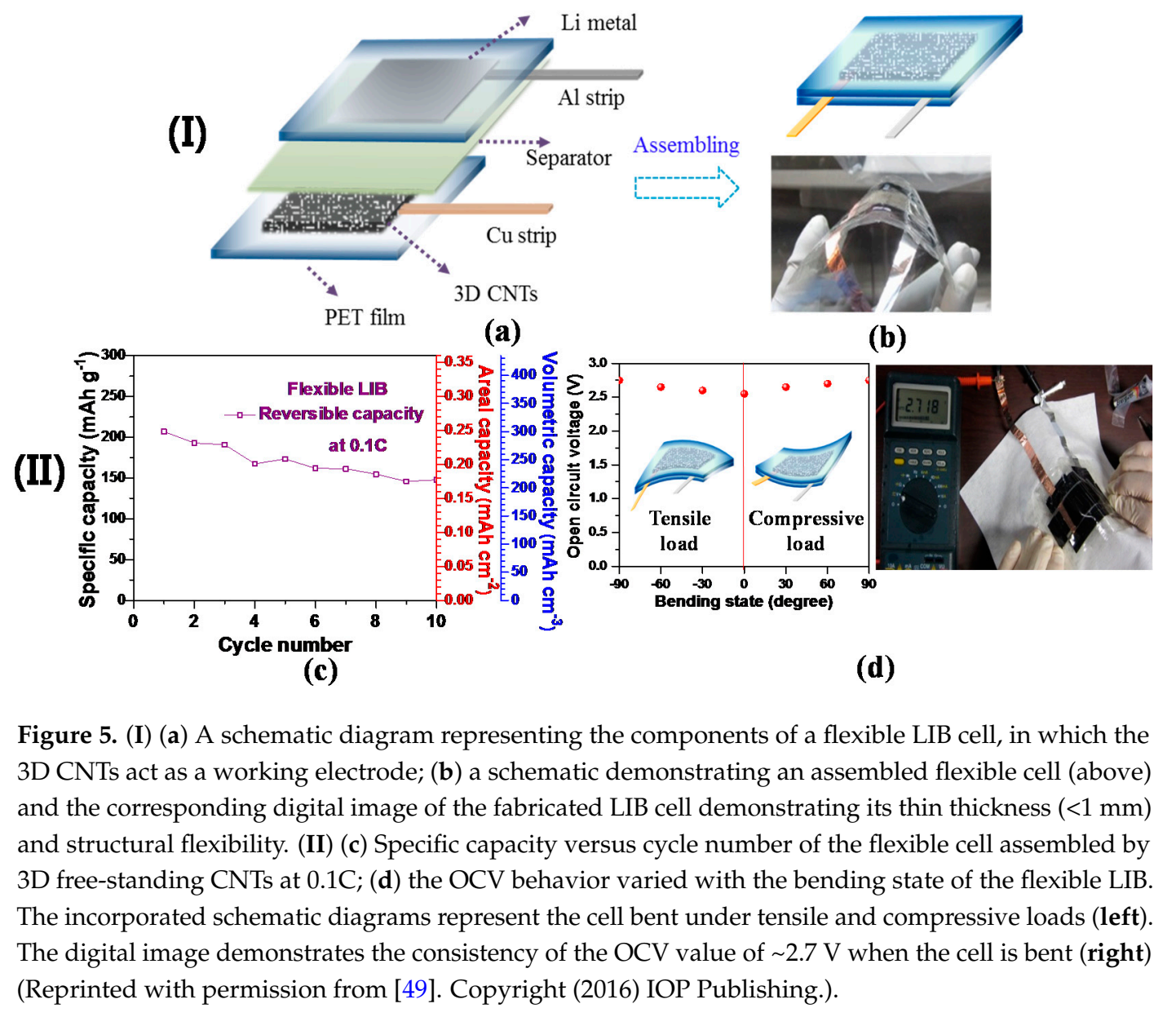

\subsection{D Carbon Nanotube-Graphene Seamless Structure}

Designing CNTs directly grown on metal has a high potential to be implemented in various device applications (e.g., supercapacitors); however, it has faced shortcomings of inadequate CNTs-metal interfacial contact and surface area utilization efficiency [105]. To overcome these shortcomings, we designed vertically aligned CNT forests directly grown on graphene fabricated on a 3D Ni substrate (hereafter, referred to as 3D CNTs-graphene-Ni) through a thermal CVD method via an $\mathrm{Fe} / \mathrm{Al}_{2} \mathrm{O}_{3}$ catalyst layer. In this unique structure, the CNTs are strongly bonded to the graphene layer by covalent bonding, forming a seamless and robust CNTs-graphene hybrid architecture (Figure 6a), while graphene serves as an interfacial layer between the CNTs and the metal to realize the direct growth of high quality CNTs on 3D Ni. Figure 6b demonstrates SEM image of the as-obtained 3D CNTs-graphene-Ni, illustrating its well-interconnected network structure. The inset of Figure $6 \mathrm{~b}$ gives a SEM image of the as-obtained structure; it also shows the length of CNTs in this structure, which was measured around $35 \mu \mathrm{m}$. The peak ratio $\left(I_{G}: I_{D}\right)$ of $G$ and $D$ (appearing at $1580 \mathrm{~cm}^{-1}$ and $1350 \mathrm{~cm}^{-1}$, respectively) of the CNTs ( 3:1) indicates a high degree of crystallinity of the CNTs from Raman spectra (Figure 6c). The presence of defects in CNTs is clarified by D peak and the defects largely stem from $\mathrm{sp}^{3}$ carbon atoms, derived during the growth process. The clear radial breathing mode (RBM) signals in the inset (left) of Figure 6c support different kinds of CNTs that are single-, double-, or triple-walled, with diameters ranging from 3 to $7 \mathrm{~nm}$, as observed from the HRTEM images in the inset (right) of Figure 6c. The well-controlled contact interface of the 3D CNTs-graphene-Ni structure could be characterized by the capacitive properties of the structure (Figure $6 \mathrm{~d}-\mathrm{f}$ ). In an electrochemical double-layer capacitor (EDLC) cell, the structure was used as an electrode, while aqueous $\mathrm{KOH}$ $(6 \mathrm{M})$ was used as the electrolyte. Figure $6 \mathrm{~d}$ shows the cyclic voltammograms (CVs) of the EDLC at various scan rates. The current response linearly increased as a function of scan rate, showing 
the typical (e.g., rectangular and symmetric) shape of the CV traces, associated with the good rate capability of the structure. Such a consistent shape of the CVs was seen at a high scan rate of $500 \mathrm{mV} / \mathrm{s}$, highlighting low-contact resistance at the interface of the 3D CNTs-graphene-Ni structure [106-108]. The Nyquist plot shown in Figure 6e reveals the frequency response of the EDLC cell ranging from $1 \mathrm{MHz}$ to $10 \mathrm{mHz}$. The line is almost parallel to the imaginary $\mathrm{Z}$ axis, indicating the ideal capacitive behavior. The resistance of electrolyte migration was determined to be $1.25 \Omega$ from the semicircle traced by the enlarged data (the inset of Figure 6e) in the high-frequency region. The Galvanostatic charge-discharge traces in Figure $6 \mathrm{f}$ can be translated to specific capacitance values of 104, 99, 101, and $100 \mathrm{~F} \cdot \mathrm{g}^{-1}$ acquired at current densities of $0.2,0.33,0.67$, and $1.00 \mathrm{~A} \cdot \mathrm{g}^{-1}$, respectively. The nearly consistent specific capacitances with the increasing scan rate until $1.00 \mathrm{~A} \cdot \mathrm{g}^{-1}$ point to the exceptional diffusion conductivity between the 3D CNTs-graphene structure and the electrolyte. These obtained values outperformed the EDLC assembled with CNTs directly grown on Inconel without graphene approximately fivefold and were also equivalent to the recently reported values of the EDLC assembled with graphene oxide [109-111]. Such an excellent electrochemical performance was largely due to the low-contact resistance at the interface of the 3D CNTs-graphene-Ni structure. This design is expected to show promising results when implemented into the application of Li-ion battery systems.
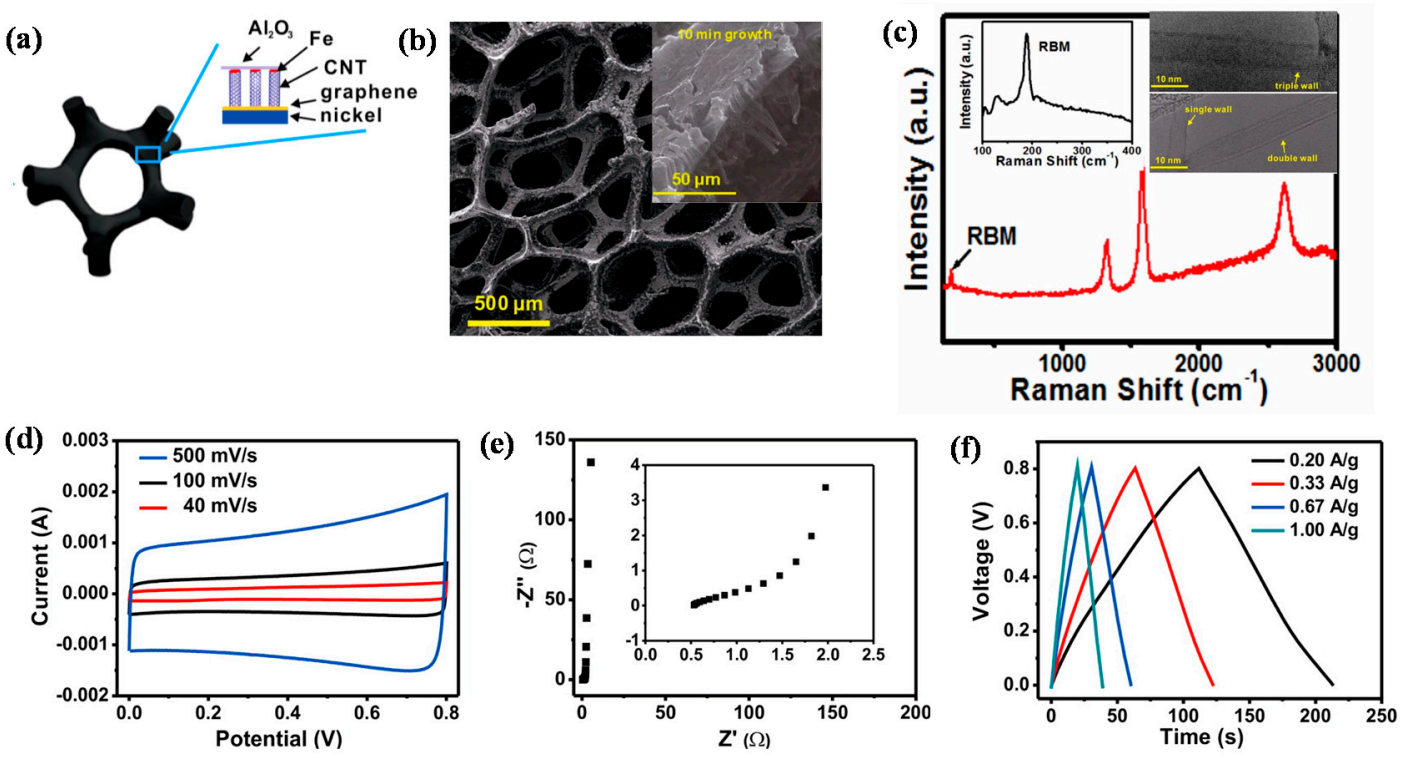

Figure 6. (a) A schematic model of a CNT forest directly grown on graphene-porous nickel while lifting the $\mathrm{Fe} / \mathrm{Al}_{2} \mathrm{O}_{3}$ catalytic layer; (b) SEM image of a CNT-graphene-porous nickel sample. The sample was synthesized using $1.5 \mathrm{~nm} \mathrm{Fe} / 10 \mathrm{~nm} \mathrm{Al}_{2} \mathrm{O}_{3}$ as the catalyst; the growth time was $10 \mathrm{~min}$. Inset shows SEM image demonstrating CNTs grown for $10 \mathrm{~min}$; the length of CNTs was $\sim 250 \mu \mathrm{m}$. (c) Raman spectra of the CNTs under $633 \mathrm{~nm}$ excitation wavelengths. Insets show spectra of the radial breathing modes (RBMs) (left) and TEM images of the CNTs with different wall numbers. (d-f) Supercapacitor performances of the devices integrated with CNT-graphene-porous nickel; (d) CV traces at different scan rates; (e) electrochemical impedance spectra. Inset demonstrates the data at high-frequency ranges. (f) Galvanostatic charge/discharge curves measured in the $6 \mathrm{M} \mathrm{KOH}$ electrolyte under different currents (Reprinted with permission from [105]. Copyright (2013) American Chemical Society.).

\subsection{D Carbon Nanotube-Graphene for Flexible LIB}

To date, carbon nanomaterial-based LIBs with flexible polymer substrates have faced drawbacks such as the low loading amount of electroactive materials and complicated fabrication processes [112]. Furthermore, higher specific and volumetric capacities of anodes featuring no metallic current collectors have been a hot topic for emerging flexible LIBs [101]. In light of these issues, a large-area patterned 3D CNTs-graphene hybrid anode structure was fabricated by a simple hot lamination 
process, transferring the CNTs grown on 3D Cu mesh onto graphene attached to a polyethylene terephthalate (PET) flexible film. In this structure, graphene served as a bridge to promote electrical conductivity throughout the 3D network of CNTs. Figure 7a-d represents the processing steps for the 3D CNTs on graphene-PET film. Good flexibility of the 3D CNTs-graphene-PET film was obtained; the physical flexibility inflicted no damage on the structure (Figure 7d). The exceptional flexibility and structural integrity were presumably attributed to pressure-sensitive adhesives coated on the commercial PET film, tethering 3D CNTs-graphene firmly to PET.

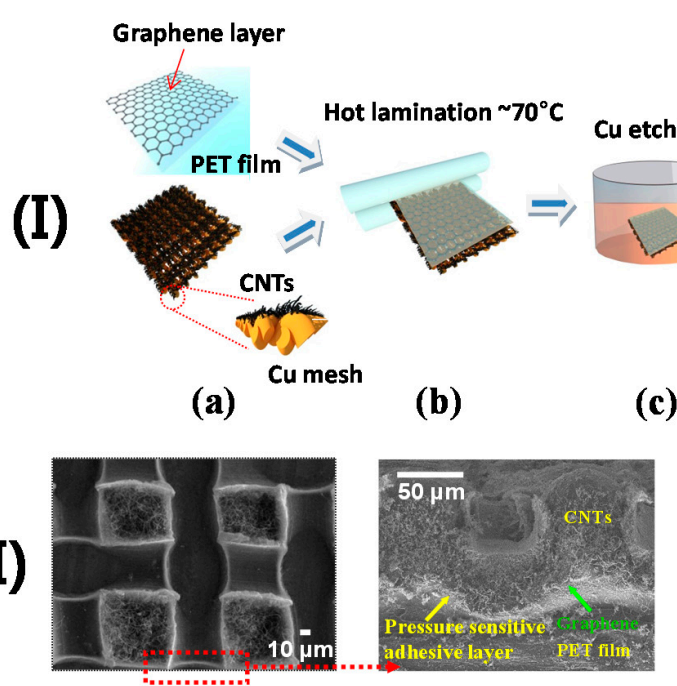

(e)

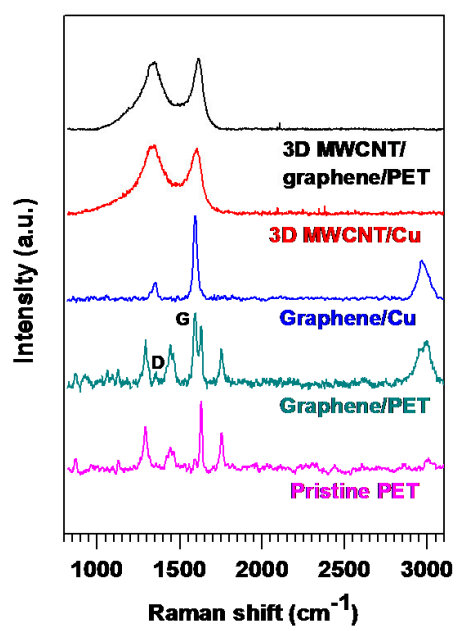

(h) (f)

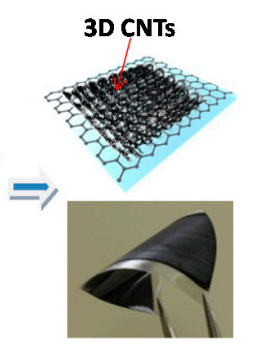

(d)

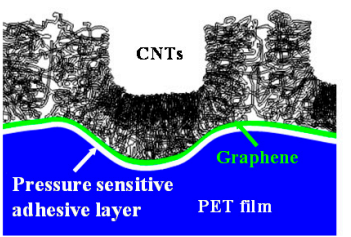

(g)

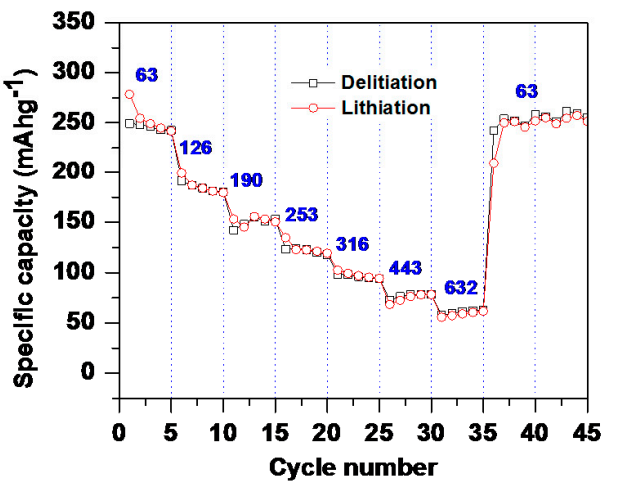

(i)

Figure 7. (I) Fabrication procedures of 3D CNTs on flexible graphene-PET substrate: (a) Graphene-PET film and 3D CNTs on $\mathrm{Cu}$; (b) hot lamination of 3D CNTs onto graphene-PET; (c) Cu removal by using $\mathrm{FeCl}_{3}$ solution; (d) 3D CNTs transferred onto the graphene-PET film. Note that the digital image demonstrates the exceptional flexibility of the 3D CNTs-graphene-PET structure. (II) Structural and electrochemical properties of 3D CNTs-graphene-PET; (e) plane-view SEM image; (f) cross-sectional SEM image; (g) schematic diagram of the cross-sectional image shown in (f); (h) Raman spectra of 3D CNTs and graphene on two different substrates $\mathrm{Cu}$ foil and PET film, and pristine PET film; (i) C-rate capability at seven different current densities, the values of which are denoted in the plot (Reprinted with permission from [63]. Copyright (2014) Elsevier.).

The patterned 3D CNT structure was successfully transferred and uniformly arrayed over the graphene-PET film, as shown in a FESEM plane view (Figure 7e). The high electrical conductivity 
(low sheet resistance of $8 \Omega / \mathrm{sq}$ ) was measured for the 3D CNTs. Once the CNTs were transferred over the PET film, the 3D CNT structure was turned upside down with respect to its original structure on 3D Cu. The FESEM image of the darker regions (compared to the brighter box regions) represents the bottom side of the 3D CNT architecture directly grown on the $\mathrm{Cu}$ mesh substrate. When pressed by a thermal laminator, the upper regions of 3D CNTs on $\mathrm{Cu}$ were filled into the free spaces (i.e., the brighter box regions in the FESEM image, corresponding to the holes in the $\mathrm{Cu}$ mesh), thus exhibiting randomly oriented CNTs (Figure 7e). Compared with a CNTs-polycarbonate (PC) film fabricated by a small-scale and costly laser-jet patterning technique, and rolled quartz cylinders [113], the 3D CNTs-graphene-PET film had the following unique features: (1) graphene layers were intermediated with both heterogeneous materials of CNTs and PET, therefore serving as an electrical conducting agent; (2) the 3D CNTs-graphene-PET film was synthesized using a simple lamination process of CNTs grown on 3D Cu mesh. The overall height of the 3D CNTs on a PET film is estimated to be $40 \mu \mathrm{m}$ and 3D CNTs are firmly adhered to PET through the adhesives coated on the PET film (Figure 7f). A schematic diagram also highlights the conformal adhesive layer by the white line, along with designation of other components (Figure $7 \mathrm{~g}$ ). Both the presence and crystallinity of CNTs and graphene are revealed by Raman spectroscopy analysis from two main peaks, G mode at $\sim 1580 \mathrm{~cm}^{-1}$ (the first-order scattering of the $\mathrm{E}_{2 \mathrm{~g}}$ phonon of $\mathrm{sp}^{2} \mathrm{C}$ atoms) and $\mathrm{D}$ mode at $\sim 1350 \mathrm{~cm}^{-1}$ (k-point photons of $A_{1 g}$ symmetry) [114]. Typical G and D peaks ensure the presence of graphene and CNTs grown on $\mathrm{Cu}$ and transferred onto a PET film (Figure 7h). Furthermore, the low degree of crystallinity of CNTs is validated by the intensity ratio of $\mathrm{D}$ to $\mathrm{G}$ mode peaks $\left(\mathrm{I}_{\mathrm{D}} / \mathrm{I}_{\mathrm{G}} \sim 1\right)$, seemingly attributed to the lower growth temperature $\left(750^{\circ} \mathrm{C}\right)$ relative to the graphitization temperature $\left(2600-3300^{\circ} \mathrm{C}\right)$.

The electrochemical characteristics of 3D CNTs-graphene as a working electrode were tested by using a 2032 coin-type half-cell, assembled with Li metal as counter and reference electrodes, and crescent-shaped $\mathrm{Cu}$ foil on the CNTs as a current collector. Specific capacities varied from $254 \mathrm{mAh} \cdot \mathrm{g}^{-1}$ to $59 \mathrm{mAh} \cdot \mathrm{g}^{-1}$ at different C-rates from $0.17 \mathrm{C}$ to $1.7 \mathrm{C}$ in a staircase manner (Figure $7 \mathrm{i}$ ), and then the specific capacity was recovered to an initial capacity of $\sim 254 \mathrm{mAh} \cdot \mathrm{g}^{-1}$ (at $0.17 \mathrm{C}$ ) after being subjected to the higher $\mathrm{C}$-rate up to 1.7C. The stable and reversible specific capacities are comparable to other values from free-standing CNT films $[13,18,19]$. These findings secure the excellent C-rate capability of the flexible LIB anode, largely ascribed to outstanding structural integrity and interfacial bonding strength of 3D CNTs-graphene on PET.

\subsection{D Carbon Nanotube-Amorphous Silicon}

Various types of hybrid anode nanostructures have been developed to induce a synergistic combination of two complementary nanomaterials for improved electrochemical performance. Recently, a 3D CNTs-silicon hybrid anode has gained great attention in obtaining the synergistic effects of 3D CNTs and silicon [45]. In this anode, 3D CNTs are used as an electrical conducting framework and structural buffer against $\sim 300 \%$ volume variation of silicon during cycling; silicon, on the other hand, functions as a high-capacity material with a theoretical capacity of $4200 \mathrm{mAh} \cdot \mathrm{g}^{-1}$. In our previous study, silicon was directly deposited onto the 3D CNTs via a sputtering method; as a result, it was possible to synthesize this anode without any complicated chemical processing steps [33]. Figure 8a illustrates the schematic of the cross-section view of CNTs grown on a single $\mathrm{Cu}$ wire, in which densely grown and larger diameter CNTs are demonstrated on the top surface area of $\mathrm{Cu}$, with relatively smaller diameter CNTs on the lateral side area. In this proposed anode, the electrochemical performance was affected by the controlled interface between the CNTs as active material and $\mathrm{Cu}$ current collector [22,115]. Amorphous $\mathrm{Si}$ (a-Si) was subsequently coated on the as-grown 3D CNTs via the sputtering method and a Ti adhesion layer was intermediated with a-Si for reinforced bonding strength between a-Si and CNTs. 


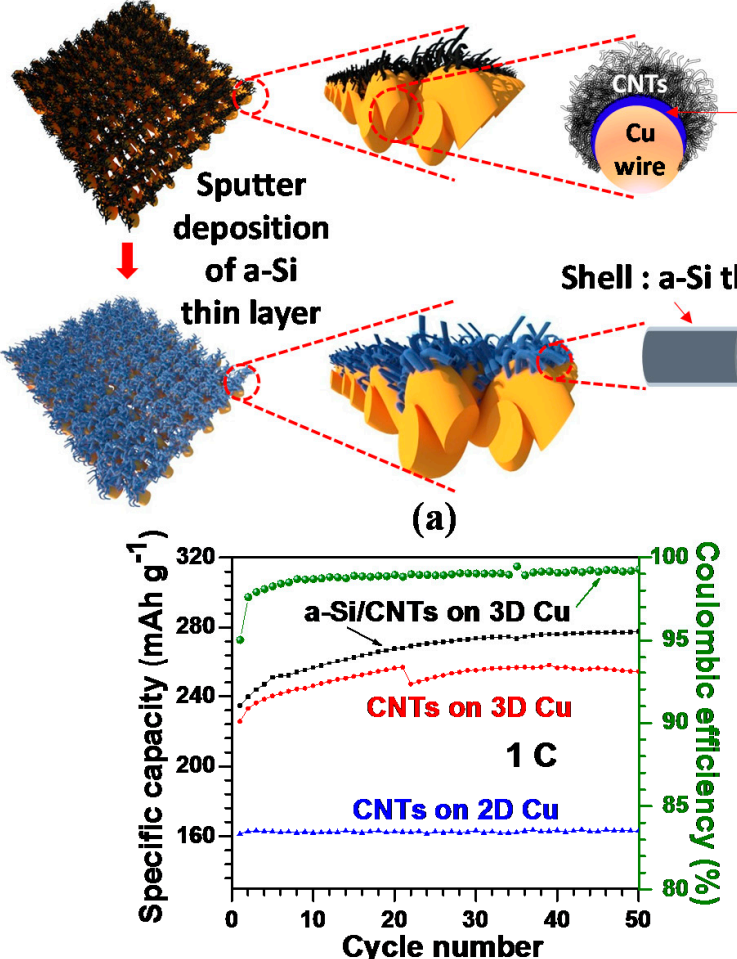

(c) TiC

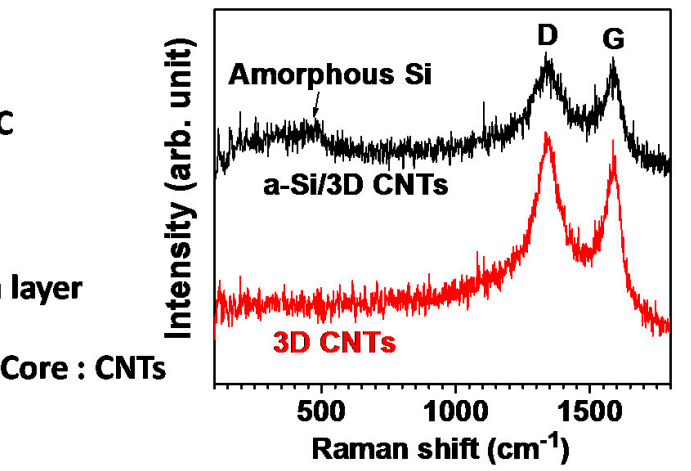

(b)

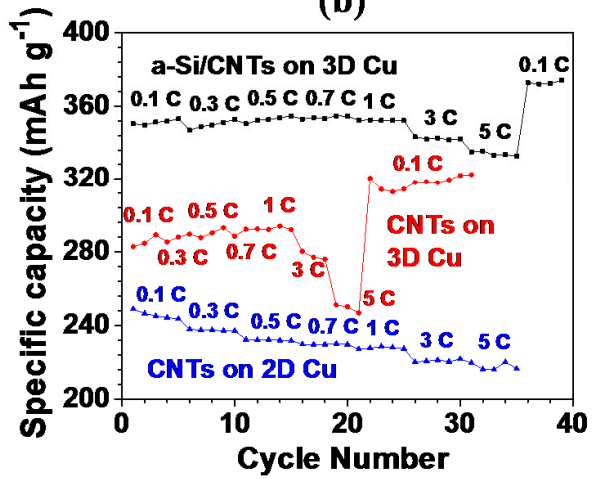

(d)

Figure 8. (a) Schematic model of CNTs grown on 3D Cu and a-Si deposited CNTs on 3D Cu; (b-d) structural and electrochemical properties of CNT-based anodes: (b) Raman spectroscopic response. Note that the broad peak at around $480 \mathrm{~cm}^{-1}$ in the a-Si/CNTs indicates the presence of amorphous $\mathrm{Si}$. (c) Comparative cycling performances of the different anode structures. Coulombic efficiency of a-Si/CNTs at $1 \mathrm{C}$ is shown. (d) The variation of reversible capacities with different $\mathrm{C}$ rates (Reprinted with permission from [33]. Copyright (2012) Elsevier.).

The high degree of defects can be seen in the high ratio of $\mathrm{I}_{\mathrm{D}} / \mathrm{I}_{\mathrm{G}}(\sim 1)$ for the CNTs in Raman spectra (Figure $8 b$ ). The larger extent of defects offers more accessible sites for $\mathrm{Li}^{+}$ion insertion into the CNT structure and the decreased diffusion length for $\mathrm{Li}^{+}$ions; as a result, the defective CNTs are more beneficial for enhancing electrochemical performance [93,94]. In the a-Si/CNTs hybrid structure, the broad intensity peak at roughly $480 \mathrm{~cm}^{-1}$ in Figure $8 \mathrm{~b}$ verifies the existence of a-Si [116].

Figure 8c presents a comparative view of the cycling stabilities acquired from the three different anode systems for 50 cycles at $1 \mathrm{C}$ (corresponding to a current density of $372 \mathrm{~mA} \mathrm{~g}^{-1}$ ). For the 3D CNTs on $\mathrm{Cu}$, the reversible capacity gradually rose from $226 \mathrm{mAh} \cdot \mathrm{g}^{-1}$ at the 1 st cycle to $258 \mathrm{mAh} \cdot \mathrm{g}^{-1}$ at the 39th cycle, and then eventually dropped slightly to $254 \mathrm{mAh} \cdot \mathrm{g}^{-1}$ up to the 50th cycle. Such a trend of increase in capacity over the entirety of the cycles is at odds with previous reports on the constant capacity of CNT [22,23]. This continuous charge and discharge process presumably activated more surface area on the close-packed and randomly oriented CNT structure. Compared with 3D CNTs, a-Si coated 3D CNTs yielded a capacity improved by nearly 10\%, suggesting an alloy formation between a-Si and Li. Nevertheless, a specific capacity of $278 \mathrm{mAh} \cdot \mathrm{g}^{-1}$ at the 50 th cycle was lower than the previous reports on Si nanotubes [117] and Si nanowires [118], potentially due to the lower weight ratio of the deposited a-Si to CNTs (below 1\%). The fairly stable cycling performance also ensured that $\mathrm{Si}-\mathrm{C}$ bonding at the interface between a-Si and CNTs was robust without causing the a-Si layer to peel off when a-Si/3D CNT anode was cycled. Additionally, in the case of CNTs on 2D Cu foil (2D CNTs), a specific capacity of $\sim 163 \mathrm{mAh} \cdot \mathrm{g}^{-1}$ was delivered up to the 50th cycle. The capacity value was $\sim 64 \%$ that of 3D CNTs, presumably attributed to a nearly $400 \%$ higher areal density of the 3D CNTs leading to greater $\mathrm{Li}^{+}$ion accommodation abilities, as discussed in Section 1. 
Coulombic efficiency (calculated by the ratio of charge (delithiation) capacity to discharge (lithiation) capacity) of a-Si/3D CNTs was recorded as higher than $98 \%$ after the 4 th cycle and then nearly $99 \%$ after the 22nd cycle (Figure 8c). This finding verified the excellent reversibility of the a-Si/3D CNTs anode, attributed to the large amount of $\mathrm{Li}^{+}$ions furnished by $\mathrm{Li}$ metal in a cell. Overall, the specific capacities of a-Si /3D CNTs are superior to 3D CNTs regardless of the C-rates (Figure 8d); an average capacity of the a-Si/3D CNTs (334 $\mathrm{mAh} \cdot \mathrm{g}^{-1}$ at 5C) outperformed 3D CNTs $\left(249 \mathrm{mAh} \cdot \mathrm{g}^{-1}\right)$ by $34 \%$. Moreover, the average capacity ratio of 5 and $0.1 \mathrm{C}$ for the a-Si/3D CNTs was measured around 0.93 , exceeding 3D CNTs (0.86) by $8 \%$. With the enhanced performance, we confirmed that a-Si thin layer incorporated with CNTs could be a promising approach toward the enhanced storage capacity for advanced LIBs. Furthermore, the overall capacities of 3D CNTs were higher than 2D CNTs over the entirety of the C-rates. The result could stem from the higher surface area contributed by a fourfold higher areal density of 3D CNTs for $\mathrm{Li}^{+}$ion insertion abilities in conjunction with facilitated $\mathrm{Li}^{+}$ion diffusion within the 3D structure.

\subsection{D Multi-Layered Structure of Graphene-Silicon Quantum Dots}

The development of inter-layers in the 3D silicon-carbon nanostructure as a hybrid anode structure is a novel approach to enhancing the electrochemical properties of the LIBs. For this anode, the inter-layer serves as an electrical conducting and structural buffering agent and is more effective than recently developed silicon-nanocarbon hybrid anodes, which do not include an inter-layer; thus, this approach can resolve the issues of cycle-induced pulverization and low electrical conductivity of silicon $[119,120]$. Inspired by this concept, our research team formed an inter-layer $\mathrm{Cu}_{3} \mathrm{Si}$ as an electrical conducting and structural buffering media in the matrix of silicon-CuO quantum dots (hereafter referred to as $\mathrm{Si-CuO} \mathrm{QD)} \mathrm{by} \mathrm{thermal} \mathrm{reduction} \mathrm{in} \mathrm{an} \mathrm{Ar}$ atmosphere [121-123]. Figure 9a represents processing flows of each synthesis step of Graphene/Silicon-CuO quantum dot (hereafter referred to as $\mathrm{Gr} / \mathrm{Si}-\mathrm{CuO} \mathrm{QD}$ ) multi-layered anode structure for LIB by using an electrophoresis deposition (EPD) technique. The graphene oxide (GO), a precursor to graphene, was fabricated through the modified Hummers method [124]. During fabrication, $\mathrm{Cu}$ was employed as anode to create the $\mathrm{Si}-\mathrm{CuO}$ formation. Similar to the graphene growth on $\mathrm{Cu}$ (anodic deposition in Figure 9a (left)), $\mathrm{Si}-\mathrm{CuO}$ thin film on $\mathrm{Cu}$ was carried out by repeating the cathodic deposition and followed by drying process until a desired thickness $(15-100 \mathrm{~nm})$ of $\mathrm{Si}-\mathrm{CuO}$ thin layer was reached. A final product of $\mathrm{Gr} / \mathrm{Si}-\mathrm{CuO}$ layered thin films was obtained by alternating anodic and cathodic depositions, as depicted by the schematic diagram (Figure $9 \mathrm{a}$ (right)). For the fabrication of inter-layer $\mathrm{Cu}_{3} \mathrm{Si}$ in $\mathrm{Si}-\mathrm{CuO} Q \mathrm{QD}$, subsequent reduction process was introduced by annealing at $400^{\circ} \mathrm{C}$ for $30 \mathrm{mins}$ in $\mathrm{Ar}$ environment with a process pressure of 50 mTorr (as opposed to a base pressure of $10^{-7} \mathrm{mTorr}$ ) in a vacuum CVD system.

In this $\mathrm{Gr} / \mathrm{Si}-\mathrm{CuO}$ QD structure, the $\mathrm{Si}-\mathrm{CuO}$ QD layer with a 15-100 nm thickness and wave-like graphene layer with a 5-10 nm thickness were stacked alternately (Figure 9b,c). The XRD pattern from the $\mathrm{Gr} / \mathrm{Si}-\mathrm{CuO}$ QD verifies the presence of components such as carbon and graphene oxide (PDF\#46-0944), amorphous $\mathrm{CuO}$ (PDF\#44-0706), poly-crystalline $\mathrm{Cu}_{3} \mathrm{Si}$ (PDF\#51-0916), and $\mathrm{Si}$, as denoted in Figure 9d. Figure 9e manifests the superior capacities of the $\mathrm{Cu}_{3} \mathrm{Si}$-formed $\mathrm{Gr} / \mathrm{Si}-\mathrm{CuO}$ QD to the $\mathrm{Gr} / \mathrm{Si}-\mathrm{CuO} \mathrm{QD}$ at the corresponding C-rates, along with a staircase-type capacity decrease as the $\mathrm{C}$-rate increases. Furthermore, the $\mathrm{Cu}_{3} \mathrm{Si}$-formed $\mathrm{Gr} / \mathrm{Si}-\mathrm{CuO}$ QD exhibited a $222 \%$ higher capacity of $2760 \mathrm{mAh} \cdot \mathrm{g}^{-1}$ at $0.5 \mathrm{C}$ than the $\mathrm{Gr} / \mathrm{Si}-\mathrm{CuO} \mathrm{QD}$, and then the capacity gradually decreased to $350 \mathrm{mAh} \cdot \mathrm{g}^{-1}$ at $5 \mathrm{C}$ with $12 \%$ capacity retention. Afterwards, once the $\mathrm{C}$-rate returned to $0.5 \mathrm{C}$, the capacity was elevated to $1810 \mathrm{mAh} \cdot \mathrm{g}^{-1}$, which is $241 \%$ higher than the $\mathrm{Gr} / \mathrm{Si}-\mathrm{CuO}$ QD at a similar $\mathrm{C}$-rate. The XRD, SEM, and Raman analyses corroborated the structural integrity of $\mathrm{Gr} / \mathrm{Si}-\mathrm{CuO}$ QD even after undergoing 100 discharge-charge cycles (see Supporting Information, Figure S1 [57]). Therefore, we confirmed the following dual functions of the inter-layer of $\mathrm{Cu}_{3} \mathrm{Si}$ for the outstanding C-rate capability and structural integrity of the $\mathrm{Gr} / \mathrm{Si}-\mathrm{CuO}$ QD structure: electrical conducting and structural cushioning media $[125,126]$. 


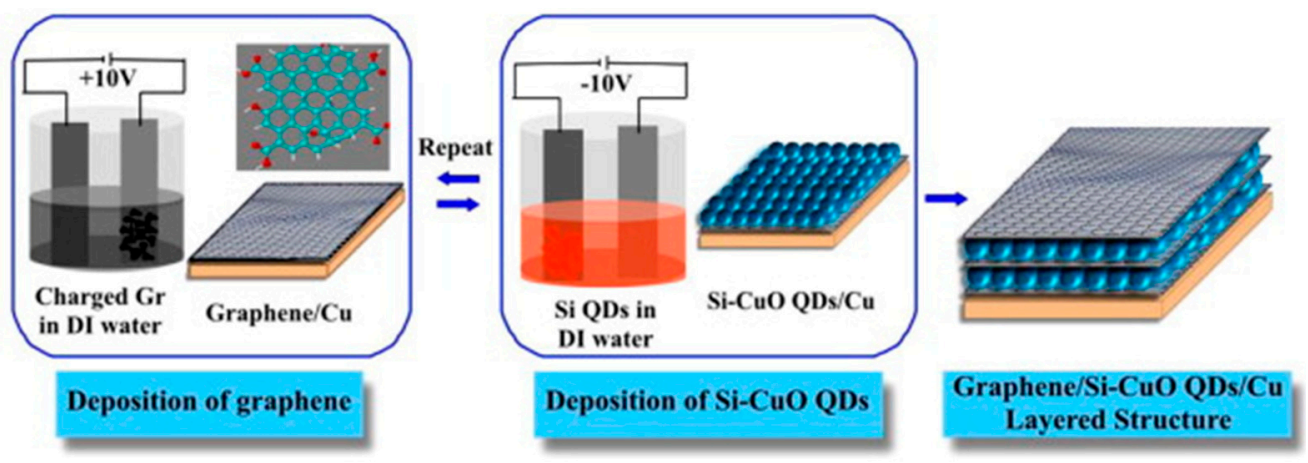

(a)

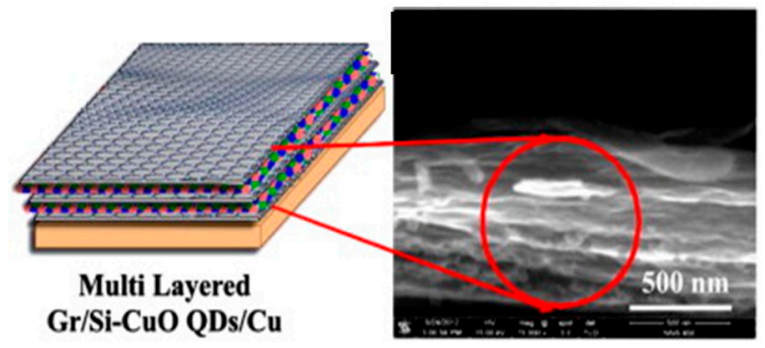

(b)

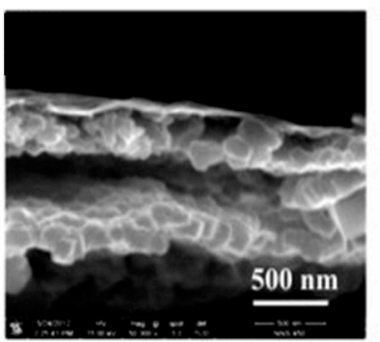

(c)

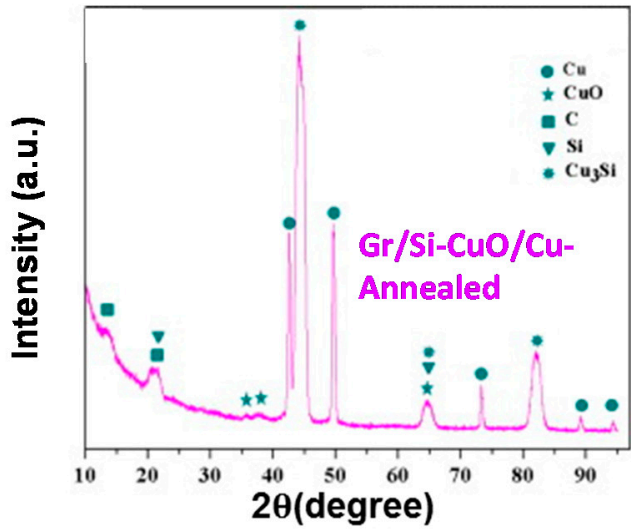

(d)

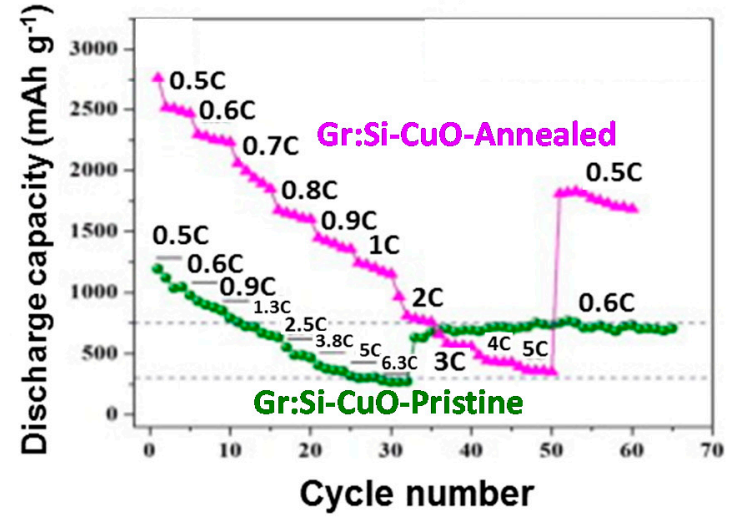

(e)

Figure 9. Schematic representation of (a) the fabrication of multi-layer $\mathrm{Gr} / \mathrm{Si}-\mathrm{CuO}$ QD through the second electrophoresis (i.e., anodic and cathodic depositions); (b,c) low and magnified FESEM cross-section images of Gr/Si-CuO QD showing the multi-layered structure of Si-CuO QD embedded into the graphene layers, including a schematic diagram of $\mathrm{Gr} / \mathrm{Si}-\mathrm{CuO}$ multilayered structure; (d) XRD pattern of annealed $\mathrm{Gr} / \mathrm{Si}-\mathrm{CuO} / \mathrm{Cu}$, verifying the presence of orthorhombic $\mathrm{Cu}_{3} \mathrm{Si}$, corresponding to the $(012)\left(2 \theta=44.5^{\circ}\right)$ and $(300)\left(2 \theta=44.9^{\circ}\right)$ planes; (e) C-rate capability of pristine Gr/Si-CuO QD and $\mathrm{Cu}_{3} \mathrm{Si}$-formed $\mathrm{Gr} / \mathrm{Si}-\mathrm{CuO}$ QD (Reprinted with permission from [57]. Copyright (2014) Elsevier.).

\section{Conclusions and Perspectives}

Efforts have been dedicated to develop 3D carbon nanostructured (e.g., CNTs, graphene, and nanoporous carbon) anodes in an attempt to implement them into advanced LIBs. The excellent electrochemical properties of these 3D carbon nanostructured anodes include high surface area, short diffusion length of $\mathrm{Li}^{+}$ions, and high loading of active materials, which further contributes to higher LIB performance than conventional carbon nanostructured anodes. Furthermore, our proposed 3D CNTs and 3D graphene networks are being used in conjunction with high-capacity electroactive materials such as nanoscale metal-oxides/silicon to form the nano-heterostructure designs. By implementing such designs, the electrochemical performances have improved significantly over those pristine electroactive materials. However, most of the carbon nanostructures face the technical 
challenge of low Coulombic efficiency (the high irreversible capacity) obtained from the first cycle, mainly associated with the solid electrolyte interphase (SEI) layer formation by the organic electrolyte decomposition. The modification of either the surface of carbon nanomaterials or the electrolyte solution could be a viable way to solve this challenge in the future. Designing 3D nanocarbon conducting networks with high-capacity electrode materials for advanced LIBs can be applied to the emerging battery systems such as Li-sulfur, Li-air, and Li-organic batteries. This direction will bring forth many potential opportunities for the development of novel carbon nanostructures in the field of energy storage.

Acknowledgments: Wonbong Choi acknowledges partial support from Air Force Office of Scientific Research (AFOSR) (FA9550-11-1-0135 and FA9550-09-1-0544). Wonbong Choi and Mumukshu D. Patel also acknowledge partial support from the Advanced Materials and Manufacturing Processes Institute (AMMPI) at UNT.

Author Contributions: Wonbong Choi directed the experiments and wrote the paper; Chiwon Kang, Eunho Cha, and Mumukshu D. Patel performed the experiments and prepared the paper. H. Felix Wu provided additional comments for this paper. Chiwon Kang, Eunho Cha, and Mumukshu D. Patel contributed equally to the paper.

Conflicts of Interest: The authors declare no conflict of interest.

\section{References}

1. Yang, Z.G.; Zhang, J.L.; Kintner-Meyer, M.C.W.; Lu, X.C.; Choi, D.W.; Lemmon, J.P.; Liu, J. Electrochemical energy storage for green grid. Chem. Rev. 2011, 111, 3577-3613. [CrossRef] [PubMed]

2. Jeong, G.; Kim, Y.U.; Kim, H.; Kim, Y.J.; Sohn, H.J. Prospective materials and applications for Li secondary batteries. Energy Environ. Sci. 2011, 4, 1986-2002. [CrossRef]

3. Winter, M.; Moeller, K.-C.; Besenhard, J.O. Carbonaceous and Graphitic Anodes. In Lithium Batteries: Science and Technology; Nazri, G.-A., Pistoia, G., Eds.; Springer: New York, NY, USA, 2004; pp. 144-194.

4. Ji, L.; Lin, Z.; Alcoutlabi, M.; Zhang, X. Recent developments in nanostructured anode materials for rechargeable lithium-ion batteries. Energy Environ. Sci. 2011, 4, 2682-2699. [CrossRef]

5. Landi, B.J.; Ganter, M.J.; Cress, C.D.; DiLeo, R.A.; Raffaelle, R.P. Carbon nanotubes for lithium ion batteries. Energy Environ. Sci. 2009, 2, 638-654. [CrossRef]

6. Yoo, E.; Kim, J.; Hosono, E.; Zhou, H.; Kudo, T.; Honma, I. Large Reversible Li Storage of Graphene Nanosheet Families for Use in Rechargeable Lithium Ion Batteries. Nano Lett. 2008, 8, 2277-2282. [CrossRef] [PubMed]

7. Ajayan, P.M.; Zhou, O.Z. Applications of Carbon Nanotubes. In Carbon Nanotubes Synthesis, Structure, Properties, and Application; Dresselhaus, M.S., Dresselhaus, G., Avouris, P., Eds.; Springer: New York, NY, USA, 2001; pp. 401-404.

8. Aricò, A.S.; Bruce, P.; Scrosati, B.; Tarascon, J.M.; Schalkwijk, W.V. Nanostructured materials for advanced energy conversion and storage devices. Nat. Mater. 2005, 4, 366-377. [CrossRef] [PubMed]

9. Che, G.; Lakshmi, B.B.; Fisher, E.R.; Martin, C.R. Carbon nanotubule membranes for electrochemical energy storage and production. Nature 1998, 393, 346-349. [CrossRef]

10. Frackowiak, E.; Gautier, S.; Gaucher, H.; Bonnamy, S.; Beguin, F. Electrochemical storage of lithium in multiwalled carbon nanotubes. Carbon 1999, 37, 61-69. [CrossRef]

11. Gao, B.; Bower, C.; Lorentzen, J.D.; Fleming, L.; Kleinhammes, A.; Tang, X.P.; McNeil, L.E.; Wu, Y.; Zhou, O. Enhanced saturation lithium composition in ball-milled single-walled carbon nanotubes. Chem. Phys. Lett. 2000, 327, 69-75. [CrossRef]

12. Shin, H.C.; Liu, M.; Sadanadan, B.; Rao, A.M. Lithium insertion into chemically etched multi-walled carbon nanotubes. J. Solid State Electrochem. 2004, 8, 908-913. [CrossRef]

13. Chen, J.; Minett, A.I.; Liu, Y.; Lynam, C.; Sherrell, P.; Wang, C.; Wallace, G.G. Direct Growth of Flexible Carbon Nanotube Electrodes. Adv. Mater. 2008, 20, 566-570. [CrossRef]

14. Wang, X.X.; Wang, J.N.; Chang, H.; Zhang, Y.F. Preparation of Short Carbon Nanotubes and Application as an Electrode Material in Li-Ion Batteries. Adv. Funct. Mater. 2007, 17, 3613-3618. [CrossRef]

15. Ng, S.H.; Wang, J.; Guo, Z.P.; Chen, J.; Wang, G.X.; Liu, H.K. Single wall carbon nanotube paper as anode for lithium-ion battery. Electrochim. Acta 2005, 51, 23-28. [CrossRef] 
16. Shah, A.; Ates, M.N.; Kotz, S.; Seo, J.; Abraham, M.; Somu, S.; Busnaina, A. A Layered Carbon Nanotube Architecture for High Power Lithium Ion Batteries. J. Electrochem. Soc. 2014, 161, A989-A995. [CrossRef]

17. Yang, S.; Huo, J.; Song, H.; Chen, X. A comparative study of electrochemical properties of two kinds of carbon nanotubes as anode materials for lithium ion batteries. Electrochim. Acta 2008, 53, 2238-2244. [CrossRef]

18. Chew, S.Y.; Ng, S.H.; Wang, J.; Novák, P.; Krumeich, F.; Chou, S.L.; Chen, J.; Liu, H.K. Flexible free-standing carbon nanotube films for model lithium-ion batteries. Carbon 2009, 47, 2976-2983. [CrossRef]

19. Yoon, S.; Lee, S.; Kim, S.; Park, K.W.; Cho, D.; Jeong, Y. Carbon nanotube film anodes for flexible lithium ion batteries. J. Power Sources 2015, 279, 495-501. [CrossRef]

20. Qie, L.; Chen, W.M.; Wang, Z.H.; Shao, Q.G.; Li, X.; Yuan, L.X.; Hu, X.L.; Zhang, W.X.; Huang, Y.H. Nitrogen-Doped Porous Carbon Nanofiber Webs as Anodes for Lithium Ion Batteries with a Superhigh Capacity and Rate Capability. Adv. Mater. 2012, 24, 2047-2050. [CrossRef] [PubMed]

21. Li, X.; Yang, J.; Hu, Y.; Wang, J.; Li, Y.; Cai, M.; Li, R.; Sun, X. Novel approach toward a binder-free and current collector-free anode configuration: Highly flexible nanoporous carbon nanotube electrodes with strong mechanical strength harvesting improved lithium storage. J. Mater. Chem. 2012, 22, 18847-18853. [CrossRef]

22. Lahiri, I.; Oh, S.W.; Hwang, J.Y.; Cho, S.; Sun, Y.K.; Banerjee, R.; Choi, W. High Capacity and Excellent Stability of Lithium Ion Battery Anode Using Interface-Controlled Binder-Free Multiwall Carbon Nanotubes Grown on Copper. ACS Nano 2010, 4, 3440-3446. [CrossRef] [PubMed]

23. Lahiri, I.; Oh, S.M.; Hwang, J.Y.; Kang, C.W.; Choi, M.S.; Jeon, H.T.; Banerjee, R.; Sun, Y.K.; Choi, W.B. Ultrathin alumina-coated carbon nanotubes as an anode for high capacity Li-ion batteries. J. Mater. Chem. 2011, 21, 13621-13626. [CrossRef]

24. Luo, B.; Zhi, L. Design and construction of three dimensional graphene-based composites for lithium ion battery applications. Energy Environ. Sci. 2015, 8, 456-477. [CrossRef]

25. Raccichini, R.; Varzi, A.; Passerini, S.; Scrosati, B. The role of graphene for electrochemical energy storage. Nat. Mater. 2015, 14, 271-279. [CrossRef] [PubMed]

26. Zhou, G.; Wang, D.W.; Yin, L.C.; Li, N.; Li, F.; Cheng, H.M. Oxygen Bridges between NiO Nanosheets and Graphene for Improvement of Lithium Storage. ACS Nano 2012, 6, 3214-3223. [CrossRef] [PubMed]

27. Hou, J.; Cao, C.; Idrees, F.; Ma, X. Hierarchical Porous Nitrogen-Doped Carbon Nanosheets Derived from Silk for Ultrahigh-Capacity Battery Anodes and Supercapacitors. ACS Nano 2015, 9, 2556-2564. [CrossRef] [PubMed]

28. Roberts, A.D.; Li, X.; Zhang, H. Porous carbon spheres and monoliths: Morphology control, pore size tuning and their applications as Li-ion battery anode materials. Chem. Soc. Rev. 2014, 43, 4341-4356. [CrossRef] [PubMed]

29. Gogotsi, Y.; Simon, P. True Performance Metrics in Electrochemical Energy Storage. Science 2011, 334, 917-918. [CrossRef] [PubMed]

30. Zhang, C.; Lv, W.; Tao, Y.; Yang, Q.H. Towards superior volumetric performance: Design and preparation of novel carbon materials for energy storage. Energy Environ. Sci. 2015, 8, 1390-1403. [CrossRef]

31. Chen, Z.; Zhang, D.; Wang, X.; Jia, X.; Wei, F.; Li, H.; Lu, Y. High-Performance Energy-Storage Architectures from Carbon Nanotubes and Nanocrystal Building Blocks. Adv. Mater. 2012, 24, 2030-2036. [CrossRef] [PubMed]

32. Novák, P.; Goers, D.; Spahr, M.E. Carbon Materials in Lithium-Ion Batteries. In Carbons for Electrochemical Energy Storage and Conversion Systems; Béguin, F., Frąckowiak, E., Eds.; CRC Press: Boca Raton, FL, USA, 2010; p. 300.

33. Kang, C.W.; Lahiri, I.; Baskaran, R.; Kim, W.G.; Sun, Y.K.; Choi, W.B. 3-dimensional carbon nanotube for Li-ion battery anode. J. Power Sources 2012, 219, 364-370. [CrossRef]

34. Dillon, S.J.; Sun, K. Microstructural design considerations for Li-ion battery systems. Curr. Opin. Solid State Mater. Sci. 2012, 16, 153-162. [CrossRef]

35. Zhang, H.; Yu, X.; Braun, P.V. Three-dimensional bicontinuous ultrafast-charge and -discharge bulk battery electrodes. Nat. Nanotechnol. 2011, 6, 277-281. [CrossRef] [PubMed]

36. Zhang, H.G.; Braun, P.V. Three-dimensional metal scaffold supported bicontinuous silicon battery anodes. Nano Lett. 2012, 12, 2778-2783. [CrossRef] [PubMed]

37. Arbizzani, C.; Beninati, S.; Lazzari, M.; Mastragostino, M. Carbon paper as three-dimensional conducting substrate for tin anodes in lithium-ion batteries. J. Power Sources 2005, 141, 149-155. [CrossRef] 
38. Cheah, S.K.; Perre, E.; Rooth, M.; Fondell, M.; Hårsta, A.; Nyholm, L.; Boman, M.; Gustafsson, T.; Lu, J.; Simon, P.; et al. Self-Supported Three-Dimensional Nanoelectrodes for Microbattery Applications. Nano Lett. 2009, 9, 3230-3233. [CrossRef] [PubMed]

39. Zhang, Y.Q.; Xia, X.H.; Wang, X.L.; Mai, Y.J.; Shi, S.J.; Tang, Y.Y.; Gu, C.G.; Tu, J.P. Three-dimensional porous nano-Ni supported silicon composite film for high-performance lithium-ion batteries. J. Power Sources 2012, 213, 106-111. [CrossRef]

40. Taberna, L.; Mitra, S.; Poizot, P.; Simon, P.; Tarascon, J.M. High rate capabilities $\mathrm{Fe}_{3} \mathrm{O}_{4}$-based $\mathrm{Cu}$ nano-architectured electrodes for lithium-ion battery applications. Nat. Mater. 2006, 5, 567-573. [CrossRef] [PubMed]

41. Kim, J.H.; Myung, S.T.; Sun, Y.K. Molten salt synthesis of $\mathrm{LiNi}_{0.5} \mathrm{Mn}_{1.5} \mathrm{O}_{4}$ spinel for $5 \mathrm{~V}$ class cathode material of Li-ion secondary battery. Electrochim. Acta 2004, 49, 219-227. [CrossRef]

42. Guo, J.C.; Wang, C.S. A polymer scaffold binder structure for high capacity silicon anode of lithium-ion battery. Chem. Commun. 2010, 46, 1428-1430. [CrossRef] [PubMed]

43. Gregorczyk, K.E.; Kozen, A.C.; Chen, X.; Schroeder, M.A.; Cao, M.N.A.; Hu, L.; Rubloff, G.W. Fabrication of 3D Core-Shell Multiwalled Carbon Nanotube@ $\mathrm{RuO}_{2}$ Lithium-Ion Battery Electrodes through a $\mathrm{RuO}_{2}$ Atomic Layer Deposition Process. ACS Nano 2015, 9, 464-473. [CrossRef] [PubMed]

44. Lahiri, I.; Choi, W. Carbon Nanostructures in Lithium Ion Batteries: Past, Present, and Future. Crit. Rev. Solid State Mater. Sci. 2013, 38, 128-166. [CrossRef]

45. De Las Casas, C.; Li, W. A review of application of carbon nanotubes for lithium ion battery anode material. J. Power Sources 2012, 208, 74-85. [CrossRef]

46. Kaskhedikar, N.A.; Maier, J. Lithium Storage in Carbon Nanostructures. Adv. Mater. 2009, 21, $2664-2680$. [CrossRef]

47. Yang, Z.; Ren, J.; Zhang, Z.; Chen, X.; Guan, G.; Qiu, L.; Zhang, Y.; Peng, H. Recent Advancement of Nanostructured Carbon for Energy. Chem. Rev. 2015, 115, 5159-5223. [CrossRef] [PubMed]

48. Lee, T.I.; Jegal, J.P.; Park, J.H.; Choi, W.H.; Lee, J.O.; Kim, K.B.; Myoung, J.M. Three-Dimensional Layer-by-Layer Anode Structure Based on $\mathrm{Co}_{3} \mathrm{O}_{4}$ Nanoplates Strongly Tied by Capillary-like Multiwall Carbon Nanotubes for Use in High-Performance Lithium-Ion Batteries. ACS Appl. Mater. Interfaces 2015, 7, 3861-3865. [CrossRef] [PubMed]

49. Kang, C.W.; Cha, E.; Baskaran, R.; Choi, W.B. Three-dimensional free-standing carbon nanotubes (CNTs) for flexible lithium-ion battery anode. Nanotechnology 2016, 27, 105402. [CrossRef] [PubMed]

50. Chen, X.; Zhu, H.; Chen, Y.C.; Shang, Y.; Cao, A.; Hu, L.; Rubloff, G.W. MWCNT $/ V_{2} \mathrm{O}_{5}$ Core/Shell Sponge for High Areal Capacity and Power Density Li-Ion Cathodes. ACS Nano 2012, 6, 7948-7955. [CrossRef] [PubMed]

51. Hu, L.; Wu, H.; Gao, Y.; Cao, A.; Li, H.; McDough, J.; Xie, X.; Zhou, M.; Cui, Y. Silicon-Carbon Nanotube Coaxial Sponge as Li-Ion Anodes with High Areal Capacity. Adv. Energy Mater. 2011, 1, 523-527. [CrossRef]

52. Hu, L.; Mantia, F.L.; Wu, H.; Xie, X.; McDonough, J.; Pasta, M.; Cui, Y. Lithium-Ion Textile Batteries with Large Areal Mass Loading. Adv. Energy Mater. 2011, 1, 1012-1017. [CrossRef]

53. Xiao, Q.; Fan, Y.; Wang, X.; Susantyoko, R.A.; Zhang, Q. A multilayer Si/CNT coaxial nanofiber LIB anode with a high areal capacity. Energy Environ. Sci. 2014, 7, 655-661. [CrossRef]

54. Li, Y.; Zhang, H.; Shen, P.K. Ultrasmall metal oxide nanoparticles anchored on three-dimensional hierarchical porous gaphene-like networks as anode for high-performance lithium ion batteries. Nano Energy 2015, 13, 563-572. [CrossRef]

55. Yang, Y.; Fan, X.; Casillas, G.; Peng, Z.; Ruan, G.; Wang, G.; Yacaman, M.J.; Tour, J.M. Three-Dimensional Nanoporous $\mathrm{Fe}_{2} \mathrm{O}_{3} / \mathrm{Fe}_{3} \mathrm{C}$-Graphene Heterogeneous Thin Films for Lithium-Ion Batteries. ACS Nano 2014, 8, 3939-3946. [CrossRef] [PubMed]

56. Xin, X.; Zhou, X.; Wang, F.; Yao, X.; Xu, X.; Zhu, Y.; Liu, Z. A 3D porous architecture of Si/graphene nanocomposite as high-performance anode materials for Li-ion batteries. J. Mater. Chem. 2012, 22, 7724-7730. [CrossRef]

57. Rangasamy, B.; Hwang, J.Y.; Choi, W.B. Multi layered Si-CuO quantum dots wrapped by graphene for high-performance anode material in lithium-ion battery. Carbon 2014, 77, 1065-1072. [CrossRef]

58. Shen, L.; Zhang, X.; Li, H.; Yuan, C.; Cao, G. Design and Tailoring of a Three-Dimensional $\mathrm{TiO}_{2}$-Graphene-Carbon Nanotube Nanocomposite for Fast Lithium Storage. J. Phys. Chem. Lett. 2011, 2, 3096-3101. [CrossRef] 
59. Li, N.; Chen, Z.; Ren, W.; Li, F.; Cheng, H.M. Flexible graphene-based lithium ion batteries with ultrafast charge and discharge rates. Proc. Natl. Acad. Sci. USA 2012, 109, 17360-17365. [CrossRef] [PubMed]

60. Tao, L.; Zai, J.; Wang, K.; Wan, Y.; Zhang, H.; Yu, C.; Xiao, Y.; Qian, X. 3D-hierarchical NiO-graphene nanosheet composites as anodes for lithium ion batteries with improved reversible capacity and cycle stability. RSC Adv. 2012, 2, 3410-3415. [CrossRef]

61. Wang, B.; Li, X.; Qiu, T.; Luo, B.; Ning, J.; Li, J.; Zhang, X.; Liang, M.; Zhi, L. High Volumetric Capacity Silicon-Based Lithium Battery Anodes by Nanoscale System Engineering. Nano Lett. 2013, 13, 5578-5584. [CrossRef] [PubMed]

62. Qin, J.; He, C.; Zhao, N.; Wang, Z.; Shi, C.; Liu, E.N.; Li, J. Graphene Networks Anchored with Sn@Graphene as Lithium Ion Battery Anode. ACS Nano 2014, 8, 1728-1738. [CrossRef] [PubMed]

63. Kang, C.W.; Baskaran, R.; Hwang, J.Y.; Ku, B.C.; Choi, W.B. Large Scale Patternable 3-Dimensional Carbon Nanotubes-Graphene Structure for Flexible Li-ion Battery. Carbon 2014, 68, 493-500. [CrossRef]

64. Li, L.; Zhou, G.; Weng, Z.; Shan, X.Y.; Li, F.; Cheng, H.M. Monolithic $\mathrm{Fe}_{2} \mathrm{O}_{3}$ /graphene hybrid for highly efficient lithium storage and arsenic removal. Carbon 2014, 67, 500-507. [CrossRef]

65. Wang, R.; Xu, C.; Sun, J.; Gao, L.; Lin, C. Flexible free-standing hollow $\mathrm{Fe}_{3} \mathrm{O}_{4}$ /graphene hybrid films for lithium-ion batteries. J. Mater. Chem. A 2013, 1, 1794-1800. [CrossRef]

66. Yu, A.; Park, H.W.; Davies, A.; Higgins, D.C.; Chen, Z.; Xiao, X. Free-Standing Layer-By-Layer Hybrid Thin Film of Graphene- $\mathrm{MnO}_{2}$ Nanotube as Anode for Lithium Ion Batteries. J. Phys. Chem. Lett. 2011, 2, 1855-1860. [CrossRef]

67. Wang, G.; Wang, B.; Wang, X.; Park, J.; Dou, S.; Ahn, H.; Kim, K. Sn/graphene nanocomposite with 3D architecture for enhanced reversible lithium storage in lithium ion batteries. J. Mater. Chem. 2009, 19, 8378-8384. [CrossRef]

68. Zhou, H.; Zhu, S.; Hibino, M.; Honma, I.; Ichihara, M. Lithium Storage in Ordered Mesoporous Carbon (CMK-3) with High Reversible Specific Energy Capacity and Good Cycling Performance. Adv. Mater. 2003, 15, 2107-2111. [CrossRef]

69. Hu, Y.S.; Adelhelm, P.; Smarsly, B.M.; Hore, S.; Antonietti, M.; Maier, J. Synthesis of Hierarchically Porous Carbon Monoliths with Highly Ordered Microstructure and Their Application in Rechargeable Lithium Batteries with High-Rate Capability. Adv. Funct. Mater. 2007, 17, 1873-1878. [CrossRef]

70. Fang, B.; Kim, M.S.; Kim, J.H.; Lim, S.; Yu, J.S. Ordered multimodal porous carbon with hierarchical nanostructure for high Li storage capacity and good cycling performance. J. Mater. Chem. 2010, 20, 10253-10259. [CrossRef]

71. Xu, Y.; Guo, J.; Wang, C. Sponge-like porous carbon/tin composite anode materials for lithium ion batteries. J. Mater. Chem. 2012, 22, 9562-9567. [CrossRef]

72. Bresser, D.; Paillard, E.; Passerini, S. Lithium-ion batteries (LIBs) for medium- and large-scale energy storage. In Advances in Batteries for Medium and Large-Scale Energy Storage; Menictas, C., Skyllas-Kazacos, M., Mariana, L.T., Eds.; Elsevier: Waltham, MA, USA, 2015; pp. 125-211.

73. Peled, E.; Menachem, C.; Bar-Tow, D.; Melman, A. Improved Graphite Anode for Lithium-Ion Batteries Chemically Bonded Solid Electrolyte Interface and Nanochannel Formation. J. Electrochem. Soc. 1996, 143, L4-L7. [CrossRef]

74. Placke, T.; Siozios, V.; Schmitz, R.; Lux, S.F.; Bieker, P.; Colle, C.; Meyer, H.; Passerini, S.; Winter, M. Influence of graphite surface modifications on the ratio of basal plane to "non-basal plane" surface area and on the anode performance in lithium ion batteries. J. Power Sources 2012, 200, 83-91. [CrossRef]

75. Yu, P.; Ritter, J.; White, R.; Popov, B. Ni-composite microencapsulated graphite as the negative electrode in lithium-ion batteries - I. Initial irreversible capacity study. J. Electrochem. Soc. 2000, 147, 1280-1285. [CrossRef]

76. Yu, P.; Ritter, J.; White, R.; Popov, B. Ni-composite microencapsulated graphite as the negative electrode in lithium-ion batteries II. Electrochemical impedance and self-discharge studies. J. Electrochem. Soc. 2000, 147, 2081-2085. [CrossRef]

77. Doi, T.; Fukutsuka, T.; Takeda, K.; Abe, T.; Miyazaki, K.; Ogumi, Z. Surface Modification of Graphitized Carbonaceous Thin-Film Electrodes with Silver for Enhancement of Interfacial Lithium-Ion Transfer. J. Phys. Chem. C 2012, 116, 12422-12425. [CrossRef]

78. Doi, T.; Takeda, K.; Fukutsuka, T.; Iriyama, Y.; Abe, T.; Ogumi, Z. Surface modification of graphitized carbonaceous materials by electropolymerization of thiophene and their effects on electrochemical properties. Carbon 2005, 43, 2352-2357. [CrossRef] 
79. Gaberscek, M.; Bele, M.; Drofenik, J.; Dominko, R.; Pejovnik, S. Improved carbon anode properties: Pretreatment of particles in polyelectrolyte solution. J. Power Sources 2001, 97-98, 67-69. [CrossRef]

80. Gaberscek, M.; Bele, M.; Drofenik, J.; Dominko, R.; Pejovnik, S. Improved carbon anode for lithium batteries - Pretreatment of carbon particles in a polyelectrolyte solution. Electrochem. Solid State Lett. 2000, 3, 171-173. [CrossRef]

81. Pan, Q.; Wang, H.; Jiang, Y. Natural graphite modified with nitrophenyl multilayers as anode materials for lithium ion batteries. J. Mater. Chem. 2007, 17, 329-334. [CrossRef]

82. Yoshio, M.; Wang, H.; Fukuda, K.; Umeno, T.; Abe, T.; Ogumi, Z. Improvement of natural graphite as a lithium-ion battery anode material, from raw flake to carbon-coated sphere. J. Mater. Chem. 2004, 14, 1754-1758. [CrossRef]

83. Yoon, S.; Kim, H.; Oh, S.M. Surface modification of graphite by coke coating for reduction of initial irreversible capacity in lithium secondary batteries. J. Power Sources 2001, 94, 68-73. [CrossRef]

84. Kim, J.-S.; Yoon, W.-Y.; Yoo, K.S.; Park, G.-S.; Lee, C.W.; Murakami, Y.; Shindo, D. Charge-discharge properties of surface-modified carbon by resin coating in Li-ion battery. J. Power Sources 2002, 104, 175-180. [CrossRef]

85. Ren, Y.; Wang, J.; Huang, X.; Ding, J. The synthesis of polypyrrole@ $\mathrm{Mn}_{3} \mathrm{O}_{4} /$ reduced graphene oxide anode with improved coulombic efficiency. Electrochim. Acta 2015, 186, 345-352. [CrossRef]

86. Fu, K.; Xue, L.; Yildiz, O.; Li, S.; Lee, H.; Li, Y.; Xu, G.; Zhou, L.; Bradford, P.D.; Zhang, X. Effect of CVD carbon coatings on Si@CNF composite as anode for lithium-ion batteries. Nano Energy 2013, 2, $976-986$. [CrossRef]

87. Wang, Q.; Li, H.; Chen, L.; Huang, X. Novel spherical microporous carbon as anode material for Li-ion batteries. Solid State Ion. 2002, 152, 43-50. [CrossRef]

88. Kang, C.W.; Patel, M.; Baskaran, R.; Jung, K.N.; Xia, C.; Shi, S.; Choi, W.B. Three-dimensional carbon nanotubes for high capacity lithium-ion batteries. J. Power Sources 2015, 299, 465-471. [CrossRef]

89. Ducati, C.; Alexandrou, I.; Chhowalla, M.; Amaratunga, G.A.J.; Robertson, J. Temperature selective growth of carbon nanotubes by chemical vapor deposition. J. Appl. Phys. 2002, 92, 3299-3303. [CrossRef]

90. Dai, H. Nanotube Growth and Characterization. In Carbon Nanotubes Synthesis, Structure, Properties, and Application; Dresselhaus, M.S., Dresselhaus, G., Avouris, P., Eds.; Springer: New York, NY, USA, 2001; pp. 30-34.

91. Baker, R.T.K.; Barber, M.A.; Harris, P.S.; Feates, F.S.; Waite, R.J. Nucleation and growth of carbon deposits from the nickel catalyzed decomposition of acetylene. J. Catal. 1972, 26, 51-62. [CrossRef]

92. Siegal, M.P.; Overmyer, D.L.; Provencio, P.P. Precise control of multiwall carbon nanotube diameters using thermal chemical vapor deposition. Appl. Phys. Lett. 2002, 80, 2171-2173. [CrossRef]

93. Shimoda, H.; Gao, B.; Tang, X.P.; Kleinhammes, A.; Fleming, L.; Wu, Y.; Zhou, O. Lithium Intercalation into Opened Single-Wall Carbon Nanotubes: Storage Capacity and Electronic Properties. Phys. Rev. Lett. 2002, 88, 015502. [CrossRef] [PubMed]

94. Eom, J.Y.; Kwon, H.S. Improved lithium insertion/extraction properties of single-walled carbon nanotubes by high-energy ball milling. J. Mater. Res. 2008, 23, 2458-2466. [CrossRef]

95. Moshtev, R.; Johnson, B. State of the art of commercial Li ion batteries. J. Power Sources 2000, 91, 86-91. [CrossRef]

96. Cui, L.F.; Hu, L.; Choi, J.W.; Cui, Y. Light-Weight Free-Standing Carbon Nanotube-Silicon Films for Anodes of Lithium Ion Batteries. ACS Nano 2010, 4, 3671-3678. [CrossRef] [PubMed]

97. Fauvarque, J.F.; Simon, P. Principles of Electrochemistry and Electrochemical Methods. In Carbons for Electrochemical Energy Storage and Conversion Systems; Béguin, F., Frąckowiak, E., Eds.; CRC Press: Boca Raton, FL, USA, 2010; pp. 7-16.

98. Sharifi, T.; Valvo, M.; Gracia-Espino, E.; Sandström, R.; Edström, K.; Wågberg, T. Hierarchical self-assembled structures based on nitrogen-doped carbon nanotubes as advanced negative electrodes for Li-ion batteries and 3D microbatteries. J. Power Sources 2015, 279, 581-592. [CrossRef]

99. Welna, D.T.; Qu, L.; Taylor, B.E.; Dai, L.; Durstock, M.F. Vertically aligned carbon nanotube electrodes for lithium-ion batteries. J. Power Sources 2011, 196, 1455-1460. [CrossRef]

100. Jeong, S.; Lee, J.P.; Ko, M.; Kim, G.; Park, S.; Cho, J. Etched Graphite with Internally Grown Si Nanowires from Pores as an Anode for High Density Li-Ion Batteries. Nano Lett. 2013, 13, 3403-3407. [CrossRef] [PubMed] 
101. Hu, Y.; Sun, X. Flexible rechargeable lithium ion batteries: Advances and challenges in materials and process technologies. J. Mater. Chem. A 2014, 2, 10712-10738. [CrossRef]

102. Verma, V.P.; Das, S.; Lahiri, I.; Choi, W.B. Large-area graphene on polymer film for flexible and transparent anode in field emission device. Appl. Phys. Lett. 2010, 96, 203108. [CrossRef]

103. Gwon, H.; Kim, H.S.; Lee, K.U.; Seo, D.H.; Park, Y.C.; Lee, Y.S.; Ahn, B.T.; Kang, K. Flexible energy storage devices based on graphene paper. Energy Environ. Sci. 2011, 4, 1277-1283. [CrossRef]

104. Wei, D.; Haque, S.; Andrew, P.; Kivioja, J.; Ryhänen, T.; Pesquera, A.; Centeno, A.; Alonso, B.; Chuvilin, A.; Zurutuza, A. Ultrathin rechargeable all-solid-state batteries based on monolayer graphene. J. Mater. Chem. A 2013, 1, 3177-3181. [CrossRef]

105. Yan, Z.; Ma, L.; Zhu, Y.; Lahiri, I.; Hahm, M.G.; Liu, Z.; Yang, S.; Xiang, C.; Lu, W.; Peng, Z.; et al. Three dimensional Metal-Graphene-Nanotube multifunctional hybrid materials. ACS Nano 2013, 7, 58-64. [CrossRef] [PubMed]

106. Talapatra, S.; Kar, S.; Pal, S.K.; Vajtai, R.; Ci, L.; Victor, P.; Shaijumon, M.M.; Kaur, S.; Nalamasu, O.; Ajayan, P.M. Direct Growth of Aligned Carbon Nanotubes on Bulk Metals. Nat. Nanotechnol. 2006, 1, 112-116. [CrossRef] [PubMed]

107. Kaempgen, M.; Chan, C.K.; Ma, J.; Cui, Y.; Gruner, G. Printable Thin Film Supercapacitors Using Single-Walled Carbon Nanotubes. Nano Lett. 2009, 9, 1872-1876. [CrossRef] [PubMed]

108. Du, C.; Yeh, J.; Pan, N. High Power Density Supercapacitors Using Locally Aligned Carbon Nanotube Electrodes. Nanotechnology 2005, 16, 350-353. [CrossRef]

109. Stoller, M.D.; Park, S.; Zhu, Y.; An, J.; Ruoff, R.S. Graphene-Based Ultracapacitors. Nano Lett. 2008, 8, 3498-3502. [CrossRef] [PubMed]

110. Zhu, Y.; Murali, S.; Stoller, M.D.; Ganesh, K.J.; Cai, W.; Ferreira, P.J.; Pirkle, A.; Wallace, R.M.; Cychosz, K.A.; Thommes, M.; et al. Carbon-Based Supercapacitors Produced by Activation of Graphene. Science 2011, 332, 1537-1541. [CrossRef] [PubMed]

111. Gao, W.; Singh, N.; Song, L.; Liu, Z.; Reddy, A.L.M.; Ci, L.; Vajtai, R.; Zhang, Q.; Wei, B.; Ajayan, P.M. Direct Laser Writing of Micro-Supercapacitors on Hydrated Graphite Oxide Films. Nat. Nanotechnol. 2011, 6, 496-500. [CrossRef] [PubMed]

112. Zhou, G.; Li, F.; Cheng, H.M. Progress in flexible lithium batteries and future prospects. Energy Environ. Sci. 2014, 7, 1307-1338. [CrossRef]

113. Cole, M.; Hiralal, P.; Ying, K.; Li, C.; Zhang, Y.; Teo, K. Dry-Transfer of Aligned Multiwalled Carbon Nanotubes for Flexible Transparent Thin Films. J. Nanomater. 2012, 272960. [CrossRef]

114. Fan, Z.J.; Yan, J.; Wei, T.; Ning, G.Q.; Zhi, L.J.; Liu, J.C. Nanographene-Constructed Carbon Nanofibers Grown on Graphene Sheets by Chemical Vapor Deposition: High-Performance Anode Materials for Lithium Ion Batteries. ACS Nano 2011, 5, 2787-2794. [CrossRef] [PubMed]

115. Lahiri, I.; Seelaboyina, R.; Hwang, J.Y.; Banerjee, R.; Choi, W.B. Enhanced field emission from multi-walled carbon nanotubes grown on pure copper substrate. Carbon 2010, 48, 1531-1538. [CrossRef]

116. Iqbal, Z.; Vepiek, S. Raman scattering from hydrogenated microcrystalline and amorphous silicon. J. Phys. C Solid State Phys. 1982, 15, 377-392. [CrossRef]

117. Park, M.H.; Kim, M.G.; Joo, J.B.; Kim, K.T.; Kim, J.Y.; Ahn, S.H.; Cui, Y.; Cho, J.P. Silicon Nanotube Battery Anodes. Nano Lett. 2009, 9, 3844-3847. [CrossRef] [PubMed]

118. Chan, C.K.; Peng, H.L.; Liu, G.; McIlwrath, K.; Zhang, X.F.; Huggins, R.A.; Cui, Y. High-performance lithium battery anodes using silicon nanowires. Nat. Nanotechnol. 2008, 3, 31-35. [CrossRef] [PubMed]

119. Bae, J. Fabrication of carbon microcapsules containing silicon nanoparticles-carbon nanotubes nanocomposite by sol-gel method for anode in lithium ion battery. J. Solid State Chem. 2011, 184, 1749-1755. [CrossRef]

120. Yang, X.; Wen, Z.; Xu, X.; Lin, B.; Huang, S. Nanosized silicon-based composite derived by in situ mechanochemical reduction for lithium ion batteries. J. Power Sources 2007, 164, 880-884. [CrossRef]

121. Yoon, S.; Lee, S.I.; Kim, H.; Sohn, H.J. Enhancement of capacity of carbon-coated Si-Cu 3 Si composite anode using metal-organic compound for lithium-ion batteries. J. Power Sources 2006, 161, 1319-1323. [CrossRef]

122. Johnson, D.C.; Mosby, J.M.; Riha, S.C.; Prieto, A.L. Synthesis of copper silicide nanocrystallites embedded in silicon nanowires for enhanced transport properties. J. Mater. Chem. 2010, 20, 1993-1998. [CrossRef]

123. Kim, I.C.; Byun, D.; Lee, J.K. Electrochemical characteristics of silicon-metals coated graphites for anode materials of lithium secondary batteries. J. Electroceram. 2006, 17, 661-665. [CrossRef] 
124. Park, S.; An, J.; Piner, R.D.; Jung, I.; Yang, D.; Velamakanni, A.; Nguyen, S.T.; Ruoff, R.S. Aqueous suspension and characterization of chemically modified graphene sheets. Chem. Mater. 2008, 20, 6592-6594. [CrossRef]

125. Boukamp, B.A.; Lesh, G.C.; Huggins, R.A. All-solid lithium electrodes with mixed-conductor matrix. J. Electrochem. Soc. 1981, 128, 725-729. [CrossRef]

126. Jung, H.; Park, M.; Yoon, Y.G.; Kim, G.B.; Joo, S.K. Amorphous silicon anode for lithium-ion rechargeable batteries. J. Power Sources 2003, 115, 346-351. [CrossRef]

(C) 2016 by the authors; licensee MDPI, Basel, Switzerland. This article is an open access article distributed under the terms and conditions of the Creative Commons Attribution (CC-BY) license (http://creativecommons.org/licenses/by/4.0/). 